\title{
Disease-modifying anti-rheumatic drugs for the management of Takayasu arteritis - a systematic review and meta-analysis
}

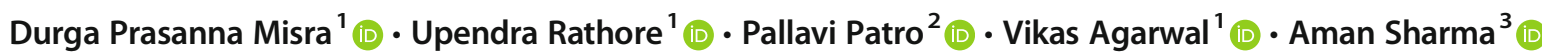

Received: 8 March 2021 / Revised: 12 April 2021 / Accepted: 18 April 2021 / Published online: 1 May 2021

(C) International League of Associations for Rheumatology (ILAR) 2021

\begin{abstract}
The pharmacotherapy of Takayasu arteritis (TAK) with disease-modifying anti-rheumatic drugs (DMARDs) is an evolving area. A systematic review of Scopus, Web of Science, Pubmed Central, clinical trial databases and recent international rheumatology conferences for interventional and observational studies reporting the effectiveness of DMARDs in TAK identified four randomized controlled trials (RCTs, with another longer-term follow-up of one RCT) and 63 observational studies. The identified trials had some concern or high risk of bias. Most observational studies were downgraded on the Newcastle-Ottawa scale due to lack of appropriate comparator groups. Studies used heterogenous outcomes of clinical responses, angiographic stabilization, normalization of inflammatory markers, reduction in vascular uptake on positron emission tomography, reduction in prednisolone doses and relapses. Tocilizumab showed benefit in a RCT compared to placebo in a secondary per-protocol analysis but not the primary intention-to-treat analysis. Abatacept failed to demonstrate benefit compared to placebo for preventing relapses in another RCT. Pooled data from uncontrolled observational studies demonstrated beneficial clinical responses and angiographic stabilization in nearly $80 \%$ patients treated with tumour necrosis factor alpha inhibitors, tocilizumab or leflunomide. Certainty of evidence for outcomes from RCTs ranged from moderate to very low and was low to very low for all observational studies. There is a paucity of high-quality evidence to guide the pharmacotherapy of TAK. Future observational studies should attempt to include appropriate comparator arms. Multicentric, adequately powered RCTs assessing both clinical and angiographic responses are necessary in TAK.
\end{abstract}

Keywords Anti-rheumatic drugs $\cdot$ Aortoarteritis $\cdot$ Biological drugs $\cdot$ Disease-modifying systematic review $\cdot$ Meta-analysis Takayasu arteritis

\section{Introduction}

Takayasu arteritis (TAK) is a granulomatous large vessel vasculitis which predominantly affects young females and is more common in Asian countries. Patients with TAK have

Both Durga Prasanna Misra and Upendra Rathore are joint first authors.

Durga Prasanna Misra

durgapmisra@gmail.com; dpmisra@sgpgi.ac.in

Upendra Rathore

upen0007@gmail.com

Pallavi Patro

patropallavi17@gmail.com

Vikas Agarwal

vikasagr@yahoo.com; vikasagr@sgpgi.ac.in

Aman Sharma

amansharma74@yahoo.com myriad manifestations. These might be either related to systemic symptoms as a part of the inflammatory response, or vascular symptoms resulting in pulse loss, pulse inequality, vascular bruits and ischemia distal to the site of vascular occlusion. Aberrant activation of the immune system underlies

1 Department of Clinical Immunology and Rheumatology, Sanjay Gandhi Postgraduate Institute of Medical Sciences (SGPGIMS), -226014, Lucknow, India

2 School of Telemedicine, Sanjay Gandhi Postgraduate Institute of Medical Sciences (SGPGIMS), -226014, Lucknow, India

3 Clinical Immunology and Rheumatology Services, Department of Internal Medicine, Postgraduate Institute of Medical Education and Research (PGIMER), -160012, Chandigarh, India 
the pathogenesis of TAK, with involvement of both innate (macrophages) and adaptive ( $\mathrm{T}$ lymphocytes) immunity in driving the disease processes in TAK. Prednisolone remains the first-line therapy in newly diagnosed, active TAK. Considering the long-term adverse effects of prednisolone [1], patients with TAK who require immunosuppressive therapy are generally initiated on a steroid-sparing disease modifying anti-rheumatic drug (DMARD) simultaneously to minimize dose and duration of corticosteroid exposure [2].

Assessment of disease activity in TAK is challenging since the onset of vascular inflammation can be insidious. Clinical outcomes of partial or complete remission have been variously defined, either dependent on physician global assessment, or based on normalization of inflammatory markers or reduction in composite disease activity indices such as the National Institutes of Health (NIH) criteria ("Kerr" criteria) for assessing disease activity in TAK or the Indian Takayasu Clinical Activity Score (ITAS 2010). Serial angiographic assessment demonstrating stabilization of vascular territory involvement, with either lack of progression or regression of vascular segments involved on angiography, is another measure of reduction of disease activity. Reduction in vascular wall metabolic activity using 18 -fluorodeoxyglucose $\left({ }^{18}\right.$ FDG) positron emission tomography computerized tomography (PET-CT) is also indicative of reduction in active disease. Reduction in prednisolone dose following therapy, reduction/ delay in number of relapses and prolongation of time of remission are other measures of control of disease activity that have been used in the literature[3].

Systematic reviews are considered the highest level of evidence in the hierarchy of evidence-based medicine. Information from systematic reviews underlies the development of recommendations or guidelines for disease management $[4,5]$. While the role of DMARD therapy in ameliorating disease activity in TAK has been the subject of previous systematic reviews[6-9], there remains a need to update this information in the context of emerging new literature regarding the pharmacotherapy of TAK. Lack of extensive database searches is another limitation of existing systematic reviews on this topic[10]. In this context, we undertook a systematic review to critically evaluate the literature supporting the use of DMARDs in the management of TAK with respect to outcomes assessed by clinical assessment, angiography and other imaging modalities, inflammatory markers and relapses.

\section{Methods}

\section{Protocol}

The systematic review protocol was pre-published[11]. We could not register the protocol on the prospective register of systematic reviews (PROSPERO) in view of the coronavirus disease 19 pandemic delaying registration of new systematic reviews on the platform. The systematic review was conducted as per the methodology prescribed by the Cochrane collaboration [12] and reported in accordance with the Preferred Reporting Standards for Systematic Reviews and Metaanalyses (PRISMA) (Supplementary Table 1) [13] and its recent amendment to describe in detail literature searches across multiple databases (PRISMA-S) (Supplementary Table 2) [14].

\section{Literature searches}

Scopus (which includes all the data on Medline), Web of Science and Pubmed Central (via Pubmed) were searched on 2 February 2021 for studies describing DMARDs in TAK, without any restrictions of date or language. Detailed search strategy is presented in Supplementary Table 3.

In addition, the past 3-year abstracts (2018-2020) of major international Rheumatology conferences (American College of Rheumatology (ACR), European Alliance of Associations for Rheumatology (EULAR), Asia-Pacific League of Associations for Rheumatology (APLAR)) and the World Health Organization (WHO) International Clinical Trials Registry Platform (ICTRP), clinicaltrials.gov and Cochrane Controlled Register of Trials (CENTRAL) were searched for clinical trials on TAK to identify any relevant studies that might have yet been unpublished but whose results were available on these platforms. Any conference abstracts that were obtained from database searches were manually searched to identify any full papers that might have been published but were missed on database searches.

\section{Inclusion criteria}

\section{Participants}

Patients diagnosed to have TAK by the clinician, or fulfilling American College of Rheumatology 1990 classification criteria [15], Ishikawa criteria [16] or Ishikawa criteria modified by Sharma [17], were included. Studies including children were classified using EULAR/Pediatric Rheumatology International Society/Pediatric Rheumatology International Trials Organization classification criteria for pediatric-onset TAK [18], American College of Rheumatology 1990 classification criteria [15] or by a clinician diagnosis. Considering that TAK is a rare disease, studies including at least five participants were included. Studies were included irrespective of the age of participants.

\section{Interventions}

Drugs which previously had been described to have a role in therapeutics of or where targeted pathways have been 
identified to play a role in pathogenesis of TAK or its counterpart large vessel vasculitis, giant cell arteritis (GCA), were included (methotrexate, azathioprine, hydroxychloroquine, mycophenolate, leflunomide, cyclophosphamide, dapsone, cyclosporine, tacrolimus, abatacept, infliximab, etanercept, adalimumab, golimumab, certolizumab, tocilizumab, ustekinumab, briakinumab, secukinumab, rituximab, tofacitinib, Janus kinase inhibitors, resveratrol, curcumin)[2, $8,9]$.

\section{Comparators}

Studies including comparators (placebo or any of the interventions described above as active comparator) as well as those without comparators were included.

\section{Outcome measures}

Due to the heterogenous outcome measures used in TAK, studies describing any of the following outcomes were included:

1. Remission based on clinical outcomes - either partial or complete remission as defined by the study investigators, or composite measures, i.e. NIH criteria[19] or ITAS2010[20].

2. Remission based on normalization of inflammatory markers.

3. Stabilization or retardation of progression on serial angiography (also referred to as angiographic stabilization).

4. Improvement in PET-CT.

5. Improvement in quality of life parameters.

6. Disease relapses following DMARD initiation.

A secondary outcome measure used was safety of DMARDs used, by evaluating the proportion of patients who developed adverse events. Post hoc secondary analyses assessed outcomes based on DMARD type (biologic versus conventional), infections in patients with DMARDs and reduction in prednisolone dose before and after DMARD therapy.

While the review protocol had proposed separate analyses of remission based on clinical outcomes and composite outcomes, the paucity of data on composite outcomes in the available studies led us to modify the protocol to analyse these two outcomes together.

\section{Type of studies}

Due to the paucity of randomized controlled trials (RCTs) in TAK[2], both observational and interventional studies were included. Observational studies which described any of the above outcomes in a defined group of patients for a defined set of DMARDs at a definite time point were included, provided such outcomes were reported in at least 5 patients. If the same cohort study described outcomes for different DMARDs in different number of TAK patients, only those outcomes reported for at least five patients were included in the synthesis of data. Studies describing outcomes for DMARDs both with and without corticosteroids were included.

\section{Exclusion criteria}

1. Original articles other than interventional studies or observational studies providing treatment outcomes with DMARDs.

2. Review articles, letter to editor not describing original data, case report or editorial.

3. Studies not directly reporting outcomes in TAK but rather reporting outcomes in other forms of large vessel vasculitis.

4. Studies presenting outcomes of corticosteroid therapy alone or endovascular/surgical interventions alone, without concomitant DMARD therapy.

5. Studies whose full text was not accessible and whose abstract did not provide adequate information relevant to the objectives of the systematic review.

6. Studies in abstract form whose full text was published elsewhere.

\section{Screening and data extraction}

All search results from Scopus, Web of Science and Pubmed Central were downloaded on to Endnote X9.3 and duplicates removed. The abstract and titles were screened independently by two investigators (DPM, PP) to identify articles of potential relevance to the objectives of the systematic review for further review, noting reasons for exclusion. Such screened articles were further screened in detail (full text where accessible, or abstracts if they provided adequate information) to identify relevant articles while noting reasons for any exclusions. Duplicate items selected from multiple databases were excluded. Further, articles that were eligible for quantitative synthesis (meta-analysis) were delineated. Differences between investigators were resolved by discussion. A flowchart to delineate the search results was prepared according to the PRISMA and PRISMA-S guidelines [13, 14].

Information from the selected articles were extracted independently by two investigators (DPM, UR) on to pre-designed proformas for uncontrolled observational studies, controlled observational studies and RCTs, which are available in the study protocol[11]. Discrepancies were resolved by mutual discussion. 


\section{Quality assessment of individual studies}

The Cochrane risk of bias 2 (RoB 2) tool was used to assess the risk of bias in the identified RCTs, evaluating five different areas (randomization, effect of assignment of intervention/ effect of adhering to intervention, missing outcome data, measurement of the outcome of interest, selective reporting of outcomes) for risk of bias. For each domain and overall, risk of bias was rated as low, some concern or high as per the instructions provided in the tool[21].

Observational studies were subject to the NewcastleOttawa scale (NOS) for cohort studies to evaluate study quality based on selection of subjects (up to four stars), comparability of subjects (up to 2 stars) and outcome assessment (up to three stars). A study could obtain a maximum of 9 stars (minimum of zero)[22]. Based on previous systematic reviews utilizing this tool, a score of 7-9 was indicative of high quality, 4-6 moderate quality and 3 or less low quality [23].

Publication bias was assessed using funnel plots if there were at least ten studies for a pair of comparisons between active interventions, or between active interventions and placebo[24, 25]. Funnel plots were generated using Stata $16.1 \mathrm{I} / \mathrm{C}$, and the egger test for evidence against the null hypothesis of no small-study effects was assessed.

\section{Certainty of evidence}

The Grading of Recommendations, Assessment, Development and Evaluations (GRADE) profiler was used to evaluate certainty of evidence for a particular outcome across multiple studies, taking into account study design, risk of bias, indirectness of evidence, inconsistency or results across studies, imprecision of estimates and other quality measures including publication bias. Based on these parameters, certainty of outcomes was rated as very low, low, moderate or high degree of certainty [26].

\section{Analysis plan}

Detailed summary of findings tables were generated separately for uncontrolled observational studies and for controlled studies (both observational and interventional) to present characteristics of the patients studied. If studies did not present means with standard deviations, these were calculated from the individual data of patients if available; otherwise, the measures provided in the study (mean, mean with range, median, median with interquartile range, median with range or range alone) were presented. Means and standard deviations across groups were pooled using online calculators for the same, wherever required [27].

Meta-analyses were performed using STATA 16.1 I/C. For uncontrolled observational studies, proportions of patients (along with 95\% confidence intervals-95\% CI) attaining at least a partial clinical response (including both those that attained a partial or complete clinical response, as stated by the study investigators), improvement in inflammatory markers, angiographic stabilization, improvement in PET$\mathrm{CT}$, proportions of relapses, percentage reduction in prednisolone dose before and after treatment (whether presented as means or medians) and proportions of patients with adverse events were pooled across studies using the metaprop command. Confidence intervals derived using the score test and Freeman-Tukey double arcsine transformation, which allowed pooling of proportions with value either 0 or 1 , were used[28]. For controlled observational studies, risk ratio of outcomes for one intervention compared to the other/ intervention compared to placebo was calculated along with their 95\% CI using online calculators[29]. These risk ratios were pooled where possible across studies using the metan command. Random effects meta-analysis was used a priori in view of heterogenous patient groups and varying followup periods. Heterogeneity of pooled estimates was assessed using the $I^{2}$ test, with values exceeding 50\% suggestive of considerable heterogeneity. For pooled results with considerable heterogeneity $\left(I^{2} \geq 50 \%\right)$, studies were excluded one at a time to evaluate whether this reduced the $I^{2}$ below $50 \%$ (thereby explaining the heterogeneity). For studies not amenable to meta-analyses, a descriptive reporting of outcomes was provided. Subgroup analyses were planned based on patient populations of adults or children, due to systematic differences between patients with childhood and adult-onset TAK described previously in the literature [30,31].

\section{Results}

Detailed search results are presented in Supplementary Table 3. The search results are described in Fig. 1. Overall, 68 studies (2089 patients with TAK) were included in the systematic review [32-99]. There were four RCTs (and a further long-term open label follow-up of one of the clinical trials, all prospective in nature), all the other studies were observational. Table 1 summarizes characteristics of uncontrolled observational studies. One study was population based[61], rest were all hospital based. Only two of the studies on biologic drugs included DMARD-naïve TAK alone [52, 87], the rest predominantly included DMARD experienced patients with few DMARD-naïve patients. None of the studies exclusively reported composite outcomes using NIH criteria or ITAS-2010 as criteria for remission, instead considered them along with other clinical response parameters. Table 2 summarizes characteristics of controlled observational studies and clinical trials. Two of the RCTs were single-centre studies, the others were multicentric. For the observational studies, 39 were single-centre studies and 24 multicentric, whereas 28 were prospective and 35 retrospective. Furthermore, 50 
studies (832 patients with TAK) from uncontrolled observational studies and 6 studies (285 patients with TAK) from controlled observational studies were synthesized in metaanalyses. The mean $( \pm$ standard deviation $)$ number of patients with TAK enrolled in each uncontrolled observational study was $16.6( \pm 14.1)$, in each controlled observational study was $56.1( \pm 34)$ and in each clinical trial was $132( \pm 117.2)$. The mean number of patients in each clinical trial was skewed considerably by two studies $[65,66]$ which included 466 patients.

\section{Assessment of risk of bias and study quality}

Table 3 presents risk of bias of the RCTs assessed using RoB 2 tool. Two studies (assessing resveratrol and curcumin versus placebo) had high risk of bias due to lack of appropriate analysis for assignment of intervention and concerns regarding outcome measurement and reporting. The RCT reporting abatacept versus placebo had some concern of risk of bias due to baseline imbalances in proportions of newly diagnosed TAK patients (none in abatacept arm, 27\% in placebo arm) as well as lesser median disease duration in the placebo arm (0.91 years) compared to abatacept ( 5.1 years). This suggested that patients in the placebo arm possibly had less severe disease. The RCT reporting tocilizumab versus placebo was deemed to have some concern about risk of bias due to lack of information about allocation concealment and the unavailability of a pre-defined statistical analysis plan.

Table 4 presents the assessment of uncontrolled observational studies using the NOS. Most studies lost points due to lack of a comparator arm. Table 5 presents the evaluation of controlled observational using the NOS. Most studies had moderate quality as per the NOS.

\section{Publication bias}

Formal assessment of publication bias was possible only for studies with at least 10 events, due to the low power of the egger test when there are smaller number of observations [25]. This could be assessed for proportions of patients with at least partial clinical response with tocilizumab (17 studies, $p$ value for egger test 0.675 , Supplementary Fig. 1a) and TNFi (15 studies, $p$ value for egger test 0.464 , Supplementary Fig. 1b), angiographic retardation or stabilization with tocilizumab (12 studies, $p$ value for egger test 0.742 , Supplementary Fig. 1c) and TNFi (10 studies, $p$ value for egger test 0.873 , Supplementary Fig. 1d). Although the funnel plot for the studies assessing at least partial clinical response to TNFi visually appeared to be asymmetrical, the formal egger test could not detect small-study effects; hence, publication bias was unlikely. A formal assessment of publication bias was not feasible for other uncontrolled studies since none of these outcomes comprised at least ten studies.

\section{Effectiveness of DMARDs}

Results are described for conventional DMARDs (cDMARDs) followed by biologic DMARDs (bDMARDs). Subsequently, results comparing two DMARDs or DMARD categories are discussed. Due to the paucity of studies in children alone, the planned subgroup analyses based on whether subjects were adults or children were not feasible.

\section{Summary results}

Following treatment with DMARDs, the proportion of patients with TAK attaining at least partial clinical remission was $78 \%$ (95\% CI 71-84\%, 46 studies, 674 patients, $I^{2}$ $73.82 \%$, Fig. 2). Angiographic stabilization was attained by $85 \%$ (95\% CI 76-92\%, 29 studies, 366 patients, $I^{2} 65.32 \%$, Fig. 3). Improvement on PET-CT was observed in $69 \%(95 \%$ CI 40-92\%, 8 studies, 64 patients, $I^{2} 72.73 \%$, Fig. $\left.4 \mathrm{a}\right)$. Normalization of inflammatory markers was noted in $90 \%$ (95\% CI 79-98\%, 8 studies, 70 patients, $I^{2} 19.04 \%$, Fig. 4b). Relapses occurred in 22\% (95\% CI 10-35\%, 16 studies, 239 patients, $I^{2} 76.75 \%$, Fig. 4c). Adverse events were observed in $18 \%$ (95\% CI 11-25\%, 36 studies, 532 patients, $I^{2}$ $68.45 \%$, Supplementary Fig. 2a). Infections occurred in $6 \%$ (95\% CI 3-11\%, 37 studies, 563 patients, $I^{2} 60.63 \%$, Supplementary Fig. 2b). Some studies presented median doses of prednisolone before and after DMARDs, whereas others presented mean doses. The median reduction in prednisolone dose following DMARDs was 81\% (95\% CI 72$90 \%$, 14 studies, $I^{2} 71.85 \%$, Supplementary Fig. 3a). The mean reduction in prednisolone dose following DMARDs was $65 \%$ (95\% CI 58-72\%, 18 studies, $I^{2} 58.63 \%$, Supplementary Fig. 3b). Except for the proportion of patients attaining normalization of inflammatory markers, all the other pooled estimates had a significant degree of heterogeneity.

Secondary analyses based on DMARD type are reported forthwith. There was only one study reporting outcomes in TAK with targeted synthetic DMARD (tofacitinib)[86]. Pooled proportion of TAK with at least a partial clinical response with bDMARDs was 84\% (95\% CI 77-89\%, 33 studies, 449 patients, $I^{2} 55.92 \%$ ) and with cDMARDs was $64 \%$ (95\% CI 47-80\%, 15 studies, 220 patients, $I^{2} 84.37 \%$ ). Angiographic stabilization with bDMARDs was observed in 86\% (95\% CI 78-93\%, 22 studies, 241 patients, $I^{2} 56.07 \%$ ) and with cDMARDs in 81\% (95\% CI 59-97\%, 6 studies, 120 patients, $I^{2} 83.55 \%$ ). All studies on PET-CT improvement were in patients on bDMARDs. Normalization of inflammatory markers was seen with bDMARDs in $92 \%$ (95\% CI 79 99\%, 7 studies, 60 patients, $I^{2} 26.34 \%$ ), one single study reported this in cDMARDs in $80 \%$ (95\% CI 44-97\%, 10 patients). Relapses were identified with bDMARDs in $26 \%$ (95\% CI 13-41\%, 11 studies, 129 patients, $I^{2} 63.4 \%$ ) and with cDMARDs in $15 \%$ (95\% CI 1-37\%, 5 studies, 110 patients). 


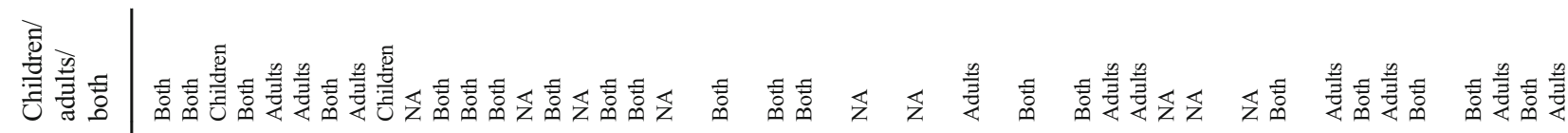

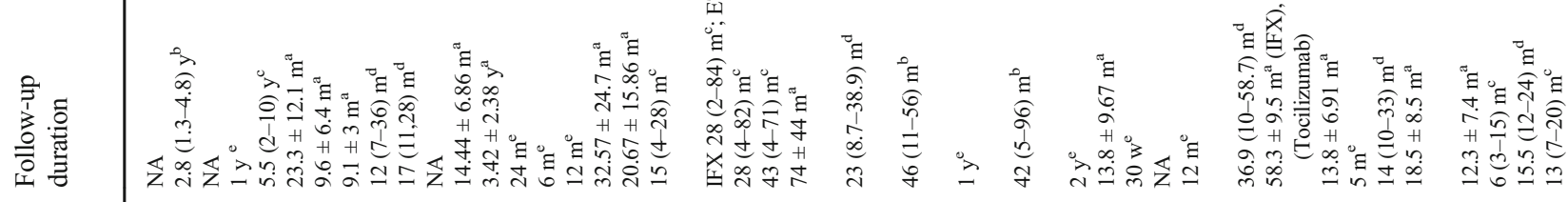

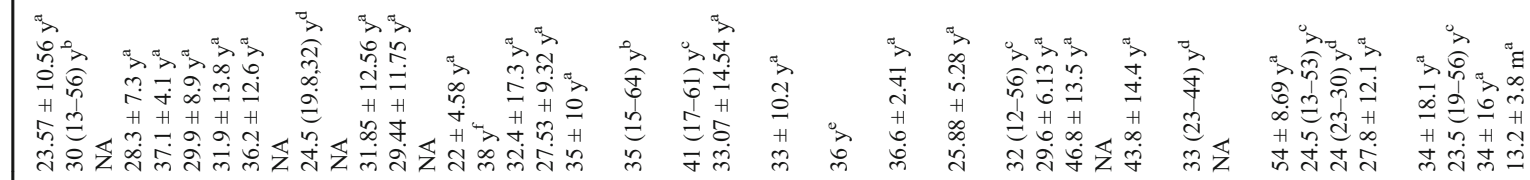

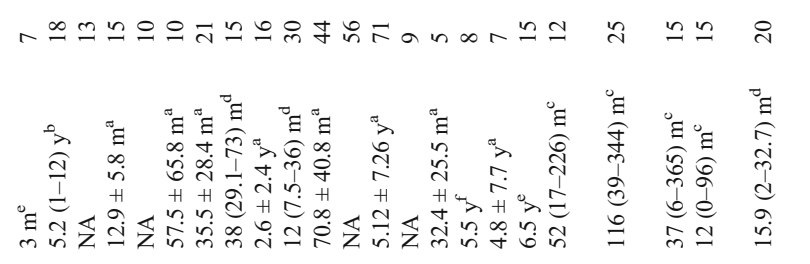

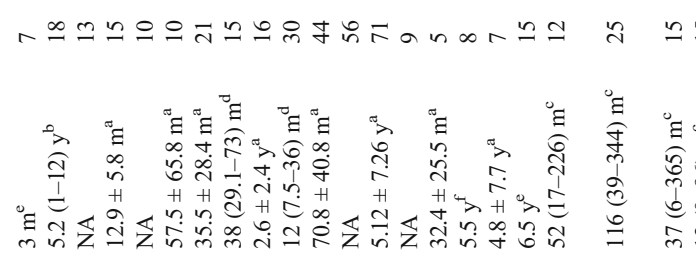

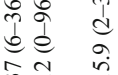

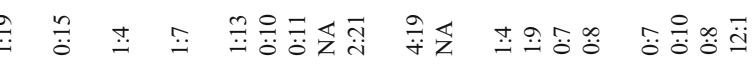

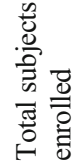

$\because 2$ ก

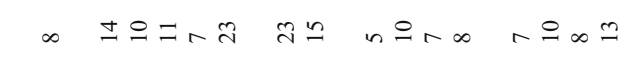

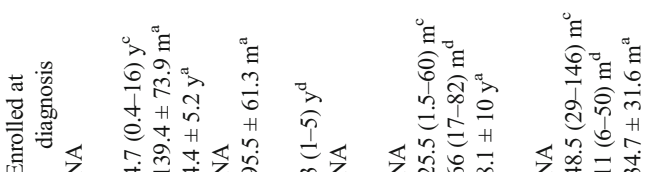

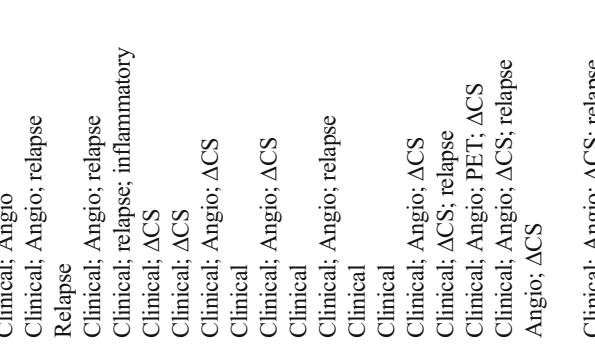

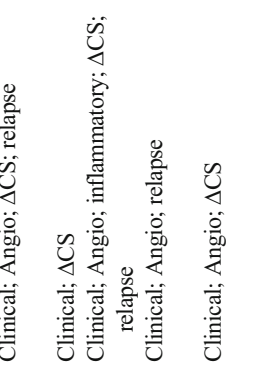

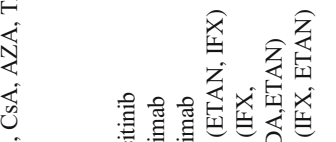

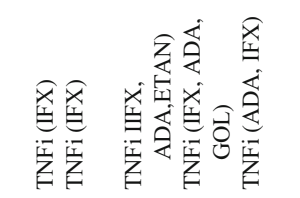

席

0

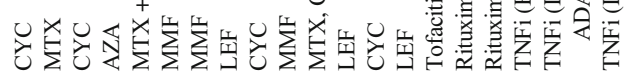

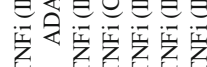

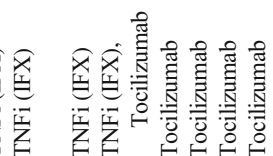

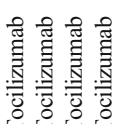

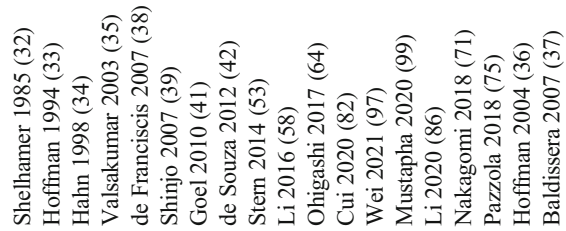

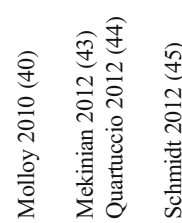

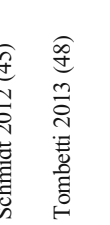

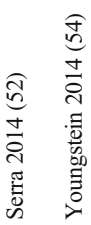

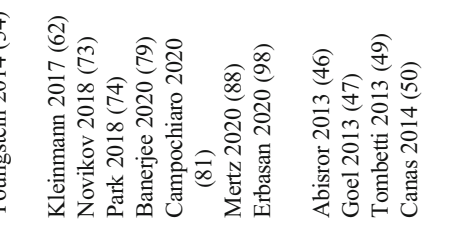

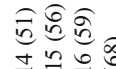

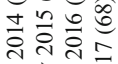

㞸

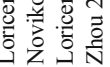




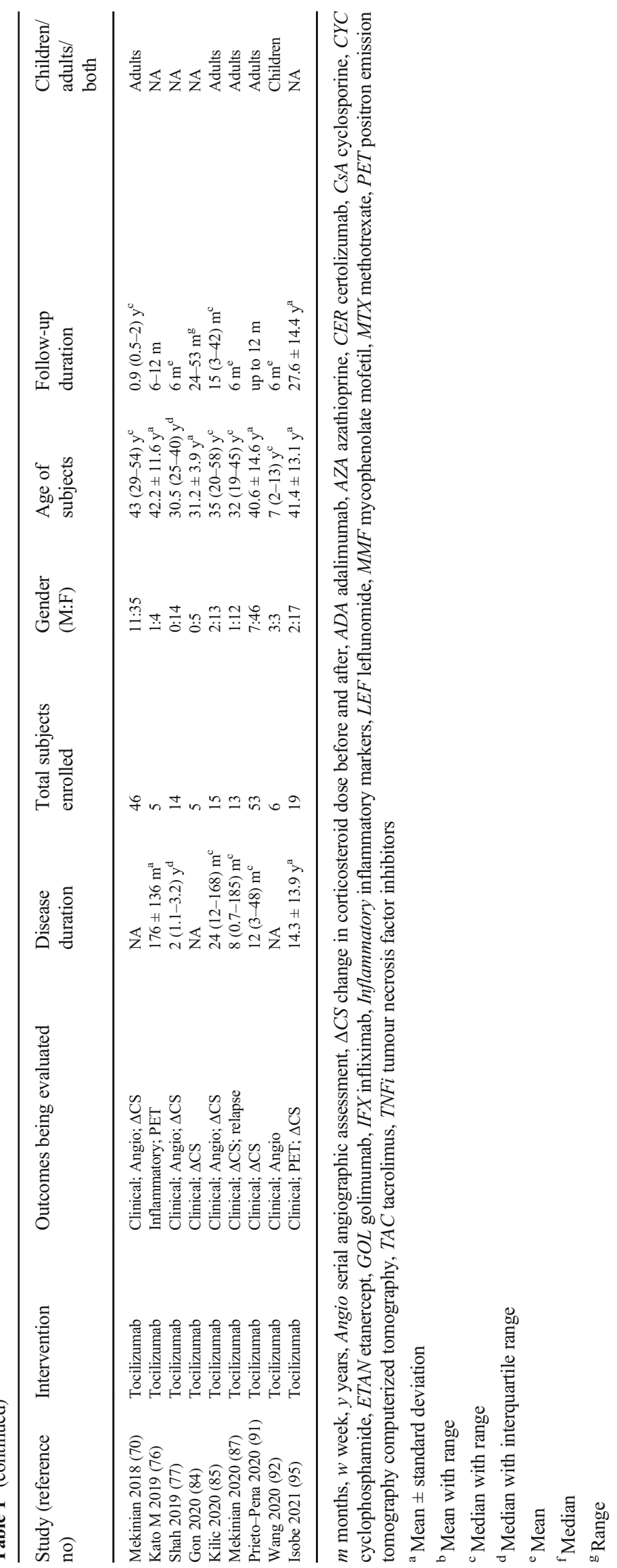




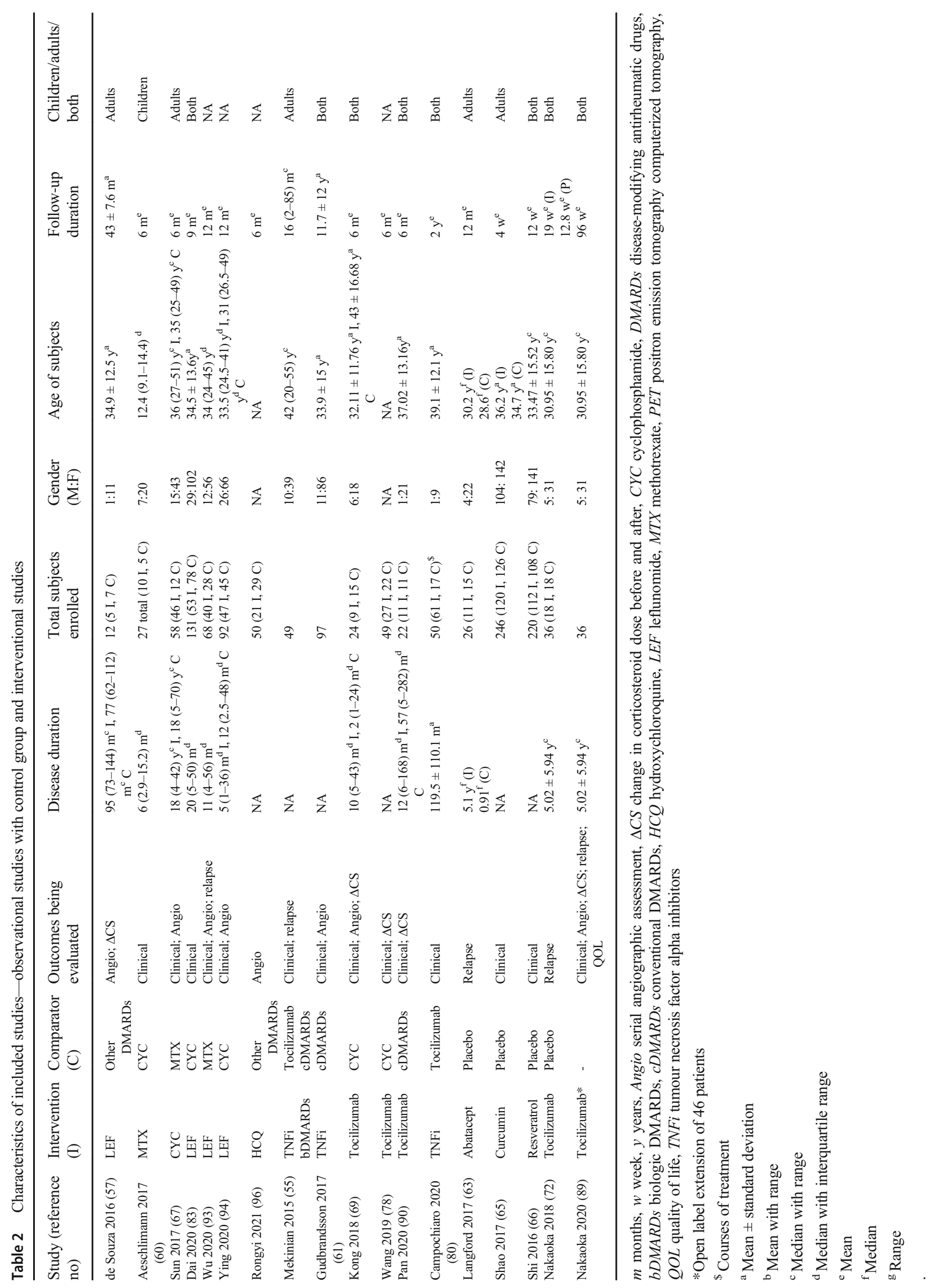


Table 3 Risk of bias for randomized controlled trials in patients with Takayasu arteritis

\begin{tabular}{|c|c|c|c|c|c|c|c|}
\hline Study (reference no) & Intervention & Randomization & $\begin{array}{l}\text { Effect of assignment } \\
\text { of intervention }\end{array}$ & $\begin{array}{l}\text { Missing outcome } \\
\text { data }\end{array}$ & $\begin{array}{l}\text { Measurement } \\
\text { of outcome }\end{array}$ & $\begin{array}{l}\text { Selection of } \\
\text { reported result }\end{array}$ & Overall \\
\hline Langford 2017 (63) & Abatacept & Some concern & Low & Low & Low & Low & Some concern \\
\hline Shao 2017 (65) & Curcumin & Some concern & High & Some concern & High & High & High \\
\hline Shi 2016 (66) & Resveratrol & Some concern & High & Low & High & High & High \\
\hline Nakaoka 2018 (72) & Tocilizumab & Some concern & Low & Low & Low & Some concern & Some concern \\
\hline
\end{tabular}

Table 4 Assessment of study quality — uncontrolled observational studies using Newcastle-Ottawa scale

\begin{tabular}{|c|c|c|c|c|c|}
\hline Study (reference no) & Intervention & Selection & Comparability & Outcome & Total \\
\hline Shelhamer 1985 (32) & $\mathrm{CYC}$ & 3 & 0 & 3 & 6 \\
\hline Hoffman 1994 (33) & MTX & 3 & 0 & 3 & 6 \\
\hline Hahn 1998 (34) & $\mathrm{CYC}$ & 3 & 0 & 3 & 6 \\
\hline Valsakumar 2003 & AZA & 3 & 0 & 3 & 6 \\
\hline de Franciscis 2007 (38) & $\mathrm{MTX}+\mathrm{CYC}$ & 2 & 0 & 3 & 5 \\
\hline Shinjo 2007 (39) & MMF & 3 & 0 & 3 & 6 \\
\hline Goel 2010 (41) & MMF & 3 & 0 & 3 & 6 \\
\hline de Souza 2012 (42) & LEF & 3 & 0 & 3 & 6 \\
\hline Stern 2014 (53) & $\mathrm{CYC}$ & 3 & 0 & 3 & 6 \\
\hline Li 2016 (58) & MMF & 3 & 0 & 3 & 6 \\
\hline Ohigashi 2017 (64) & MTX, CSA, AZA, TAC & 3 & 0 & 3 & 6 \\
\hline Cui 2020 (82) & LEF & 3 & 0 & 3 & 6 \\
\hline Wei 2021 (97) & $\mathrm{CYC}$ & 3 & 0 & 3 & 6 \\
\hline Mustapha 2020 (99) & LEF & 1 & 0 & 3 & 4 \\
\hline Li $2020(86)$ & Tofacitinib & 3 & 0 & 3 & 6 \\
\hline Nakagomi 2018 (71) & Rituximab & 2 & 0 & 3 & 5 \\
\hline Pazzola 2018 (75) & Rituximab & 3 & 0 & 3 & 6 \\
\hline Hoffman 2004 (36) & TNFi (ETAN, IFX) & 3 & 0 & 3 & 6 \\
\hline Baldissera 2007 (37) & TNFi (IFX, ADA, ETAN) & 2 & 0 & 3 & 5 \\
\hline Molloy 2010 (40) & TNFi (IFX, ETAN) & 3 & 0 & 3 & 6 \\
\hline Mekininan 2012 (43) & TNFi (IFX) & 3 & 0 & 3 & 6 \\
\hline Quartuccio 2012 (44) & TNFi (IFX) & 2 & 0 & 2 & 4 \\
\hline Schmidt 2012 (45) & TNFi IIFX, ADA, ETAN) & 3 & 0 & 3 & 6 \\
\hline Tombetti 2013 (48) & TNFi (IFX, ADA, GOL) & 2 & 0 & 2 & 4 \\
\hline Serra 2014 (52) & TNFi (ADA, IFX) & 3 & 0 & 3 & 6 \\
\hline Youngstein 2014 (54) & TNFi (IFX, ADA, ETAN) & 3 & 0 & 3 & 6 \\
\hline Kleinmann 2017 (62) & TNFi (IFX) & 3 & 0 & 3 & 6 \\
\hline Novikov 2018 (73) & TNFi (CER) & 3 & 0 & 3 & 6 \\
\hline Park 2018 (74) & TNFi (IFX) & 3 & 0 & 3 & 6 \\
\hline Banerjee 2020 (79) & TNFi (IFX) & 2 & 0 & 3 & 5 \\
\hline Campochiaro 2020 (81) & TNFi (IFX) & 3 & 0 & 3 & 6 \\
\hline Mertz 2020 (88) & TNFi (IFX) & 3 & 0 & 3 & 6 \\
\hline Erbasan 2020 (98) & TNFi (IFX), Tocilizumab & 3 & 0 & 3 & 6 \\
\hline Abisror 2013 (46) & Tocilizumab & 3 & 0 & 3 & 6 \\
\hline Goel 2013 (47) & Tocilizumab & 3 & 0 & 2 & 5 \\
\hline Tombetti 2013 (49) & Tocilizumab & 3 & 0 & 3 & 6 \\
\hline Canas $2014(50)$ & Tocilizumab & 3 & 0 & 3 & 6 \\
\hline Loricera 2014 (51) & Tocilizumab & 3 & 0 & 3 & 6 \\
\hline Novikov 2015 (56) & Tocilizumab & 2 & 0 & 3 & 5 \\
\hline Loricera 2016 (59) & Tocilizumab & 3 & 0 & 3 & 6 \\
\hline Zhou 2017 (68) & Tocilizumab & 3 & 0 & 3 & 6 \\
\hline Mekinian 2018 (70) & Tocilizumab & 4 & 2 & 3 & 9 \\
\hline Kato M 2019 (76) & Tocilizumab & 3 & 0 & 3 & 6 \\
\hline Shah 2019 (77) & Tocilizumab & 3 & 0 & 3 & 6 \\
\hline Gon 2020 (84) & Tocilizumab & 3 & 0 & 3 & 6 \\
\hline Kilic 2020 (85) & Tocilizumab & 3 & 0 & 3 & 6 \\
\hline Mekinian 2020 (87) & Tocilizumab & 3 & 0 & 3 & 6 \\
\hline Prieto-Pena 2020 (91) & Tocilizumab & 3 & 0 & 2 & 5 \\
\hline Wang 2020 (92) & Tocilizumab & 2 & 0 & 3 & 5 \\
\hline Isobe 2021 (95) & Tocilizumab & 3 & 0 & 3 & 6 \\
\hline
\end{tabular}

AZA azathioprine, $A D A$ adalimumab, $C E R$ certolizumab, $C Y C$ cyclophosphamide, ETAN etanercept, $G O L$ golimumab, IFX infliximab, $L E F$ leflunomide, $M M F$ mycophenolate mofetil, $M T X$ methotrexate, $T N F i$ tumour necrosis factor alpha inhibitors 
Table 5 Assessment of study quality - observational studies* with control group using Newcastle-Ottawa scale

\begin{tabular}{lllllll}
\hline Study (reference no) & Intervention & Comparator & Selection & Comparability & Outcome & Total \\
\hline de Souza 2016 (57) & LEF & other & 4 & 0 & 3 & 7 \\
Aeschlimann 2017 (60) & MTX & CYC & 3 & 0 & 3 & 6 \\
Sun 2017 (67) & CYC & MTX & 3 & 0 & 3 & 6 \\
Dai 2020 (83) & LEF & CYC & 4 & 2 & 3 & 9 \\
Wu 2020 (93) & LEF & MTX & 3 & 0 & 3 & 6 \\
Ying 2020 (94) & LEF & CYC & 4 & 2 & 3 & 9 \\
Mekinian 2015 (55) & TNFi & Tocilizumab & 4 & 1 & 2 & 7 \\
Gudbrandsson 2017 & TNFi & cDMARDs & 4 & 0 & 3 & 7 \\
$\quad$ (61) & Tocilizumab & CYC & 4 & 0 & 3 & 7 \\
Kong 2018 (69) & Tocilizumab & CYC & 3 & 0 & 3 & 6 \\
Wang 2019 (78) & Tocilizumab & cDMARDs & 4 & 0 & 3 & 7 \\
Pan 2020 (90) & TNFi & Tocilizumab & 4 & 0 & 3 & 7 \\
Campochiaro 2020 & & & & & \\
$\quad$ 80) & & & & & & 7 \\
\hline
\end{tabular}

$C Y C$ cyclophosphamide, DMARDs disease-modifying anti-rheumatic drugs, $C D M A R D s$ conventional DMARDs, $L E F$ leflunomide, $H C Q$ hydroxychloroquine, MTX methotrexate, $T N F i$ tumour necrosis factor alpha inhibitors *Newcastle-Ottawa Scale could not be assessed for Rongyi 2021 (95) due to inability to access the full text of the paper

Adverse events were noted in $21 \%$ on bDMARDs $(95 \%$ CI $14-28 \%, 27$ studies, 364 patients, $\left.I^{2} 57.27 \%\right)$ and $13 \%$ on cDMARDs (95\% CI $2-30 \%, 8$ studies, 163 patients, $\left.I^{2} 82.54 \%\right)$. Infections occurred in $8 \%$ on bDMARDs (95\% CI 3-14\%, 28 studies, 379 patients, $\left.I^{2} 60.91 \%\right)$ and $2 \%$ on cDMARDs (95\% CI $0-6 \%, 8$ studies, 179 patients, $I^{2} 33.14 \%$ ). All studies reporting median dose reduction in prednisolone were bDMARDs.
The mean reduction in prednisolone dose following bDMARDs was 70\% (95\% CI 62-77\%, 12 studies, $I^{2}$ $43.07 \%)$ and following cDMARDs was $63 \%$ (95\% CI $52-74 \%, 5$ studies, $\left.I^{2} 52.92 \%\right)$. The heterogeneity in pooled estimates could be partially explained by subgrouping type of DMARDs for the outcomes of infectious adverse events and mean reduction in prednisolone dose but not for the other outcomes.

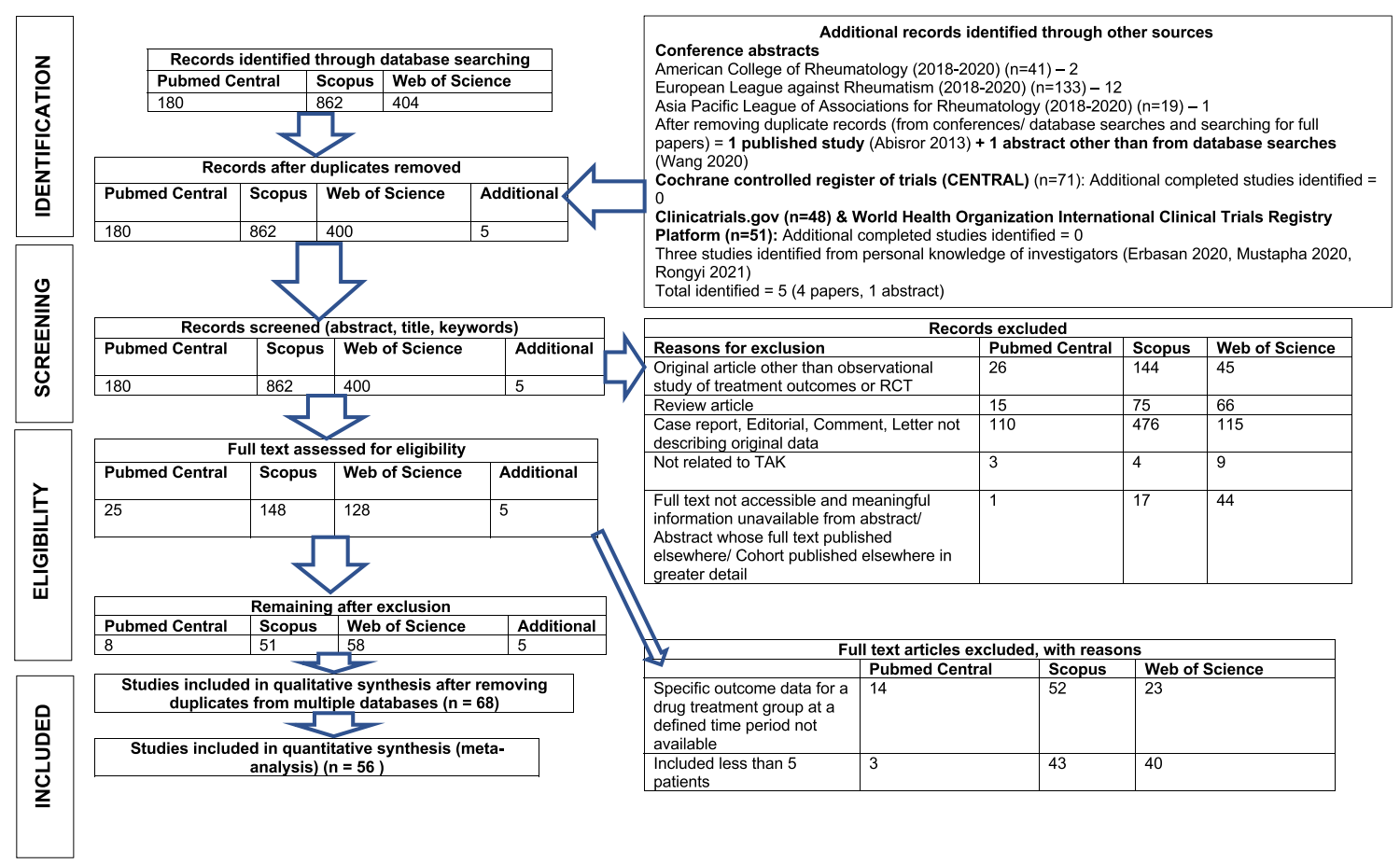

Fig. 1 Search results (adapted from the PRISMA flow diagram [13]) 


\section{Conventional DMARDs}

Methotrexate Five observational studies assessed methotrexate in TAK $[33,60,64,67,93]$. Among the two studies reporting outcomes with methotrexate alone [33, 64], pooled proportion of patients attaining at least partial clinical response was $50 \%\left(95 \%\right.$ CI $33-67 \%, 34$ patients, $\mathrm{I}^{2}$ not assessable, Fig. 2). One study assessed angiographic stabilization $(88 \%$, 95\%CI 62-98\%, 16 patients, Fig. $3)$ [33] and proportions of relapses $(44 \%$, 95\% CI 20$70 \%, 16$ patients, Fig. 4c)[33]. The three studies comparing methotrexate with other DMARDs [60, 67, 93] shall be discussed subsequently.

Azathioprine Two observational studies assessed azathioprine in TAK $[35,64]$. The pooled proportion of patients attaining at least a partial clinical response was 84\% (95\% CI 64-98\%, 22 patients, $I^{2}$ not assessable, Fig. 2). One study with 15 patients assessed angiographic stabilization (100\%, 95\% CI 78-100\%, Fig. 3), relapses $(0 \%, 95 \%$ CI 0-22\%, Fig. 4c) and proportions of patients with adverse events $(0 \%, 95 \%$ CI $0-22 \%$, Supplementary Fig. 2a)[35].

Cyclophosphamide Ten observational studies evaluated cyclophosphamide in TAK $[32,34,53,60,67,69,78,83$, 94, 97], including three uncontrolled studies [32, 34, 53] where no direct comparison could be made with DMARDs. Pooled proportion of patients with at least partial clinical response was 48\% (95\% CI 27-69\%, 2 studies, 23 patients, $I^{2}$ not assessable, Fig. 2). One study each assessed angiographic stabilization $(67 \%$, 95\% CI $22-$ $96 \%, 6$ patients, Fig. 3)[32], relapses $(15 \%, 95 \%$ CI $2-$ 45\%, 13 patients, Fig. 4c)[34] and proportion of patients with adverse events $(100 \%, 95 \%$ CI 59-100\%, 7 patients, Supplementary Fig. 2a)[32]. Wei et al. reported that the event free survival for patients on cyclophosphamide (compared to those without) at 1 year was $100 \%$ (versus $86 \%$ ) and at 5 years was $72.2 \%$ (versus $46.3 \%$ ) [97]. Using multivariable-adjusted Cox regression, the use of cyclophosphamide was associated with decreased hazard
Fig. 2 Forest plot for proportions of patients with Takayasu arteritis (TAK) with at least a partial clinical response from observational studies. 95\% CI 95\% confidence intervals, ES effect size, TNFi tumour necrosis factor alpha inhibitors

\section{Proportion of TAK having at least partial clinical response}

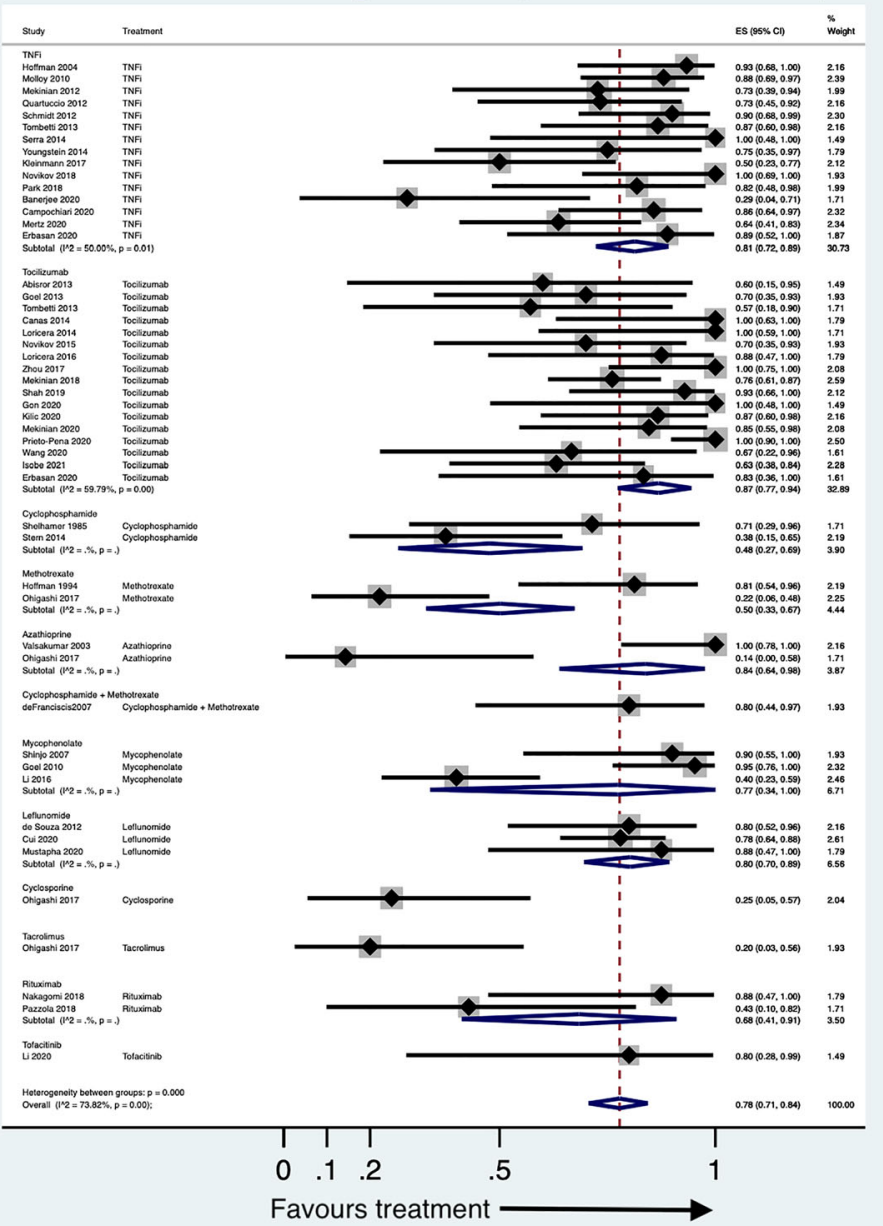


Fig. 3 Forest plot for proportions of patients with Takayasu arteritis (TAK) with angiographic stabilization from observational studies. 95\% CI 95\% confidence intervals, ES effect size, TNFi tumour necrosis factor alpha inhibitors
Proportion of TAK with angiographic retardation or improvement

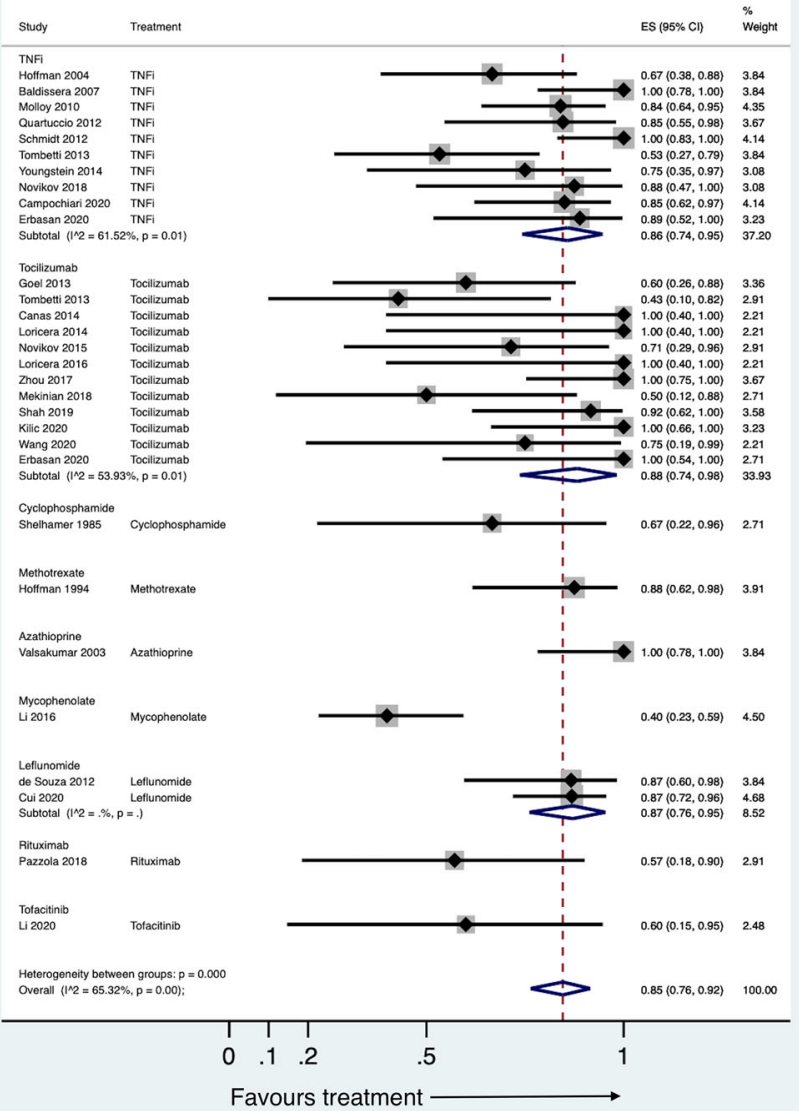

of poor prognosis by $38 \%$ (HR $0.62,95 \%$ CI $0.39-0.98$ ) [97].

The remaining six studies comparing cyclophosphamide to other therapies shall be discussed subsequently [60, 67, 69, $78,83,94]$.

Mycophenolate mofetil Three uncontrolled observational studies assessed the role of mycophenolate mofetil in TAK [39, 41, 58]. The pooled proportion of patients attaining at least a partial clinical response was $77 \%$ (95\% CI $34-100 \%, 3$ studies, 61 patients, $I^{2}$ not assessable, Fig. 2). One study reported angiographic stabilization in $40 \%$ (95\% CI 23-59\%, 30 patients, Fig. 3)[58]. The pooled reduction in mean prednisolone dose following mycophenolate mofetil was $66 \%$ (95\% CI 47-83\%, 3 studies, $I^{2}$ not assessable, Supplementary Fig. 3b). Adverse events were seen in $9 \%$ patients $(95 \%$ CI $2-$ $18 \%, 3$ studies, 61 patients, $I^{2}$ not assessable, Supplementary Fig. 2a).

Leflunomide Six observational studies (and a seventh study, a longer-term follow-up of one of the previous ones) assessed leflunomide in TAK [42, 57, 82, 83, 93,
94, 99]. For the three uncontrolled observational studies, the pooled proportion of patients achieving at least a partial clinical response was $80 \%$ (95\% CI 70-89\%, 3 studies, 73 patients, $I^{2}$ not assessable, Fig. 2), angiographic stabilization was observed in $87 \%$ (95\% CI 76-95\%, 2 studies, 53 patients, $I^{2}$ not assessable, Fig. 3) and reduction of mean prednisolone dose following leflunomide was $59 \%$ (95\% CI $46-71 \%, 2$ studies, $I^{2}$ not assessable, Supplementary Fig. 3b). One study assessed relapses (4\%, 95\% CI 0-12\%, 56 patients, Fig. 4c) [82]. The pooled proportion of patients with adverse events was $8 \%(95 \%$ CI $1-19 \%$, 3 studies, 80 patients, $I^{2}$ not assessable, Supplementary Fig. 2a).

The four studies comparing leflunomide with other DMARDs [57, 83, 93, 94] shall be subsequently discussed.

Cyclosporine One observational study reported at least partial clinical response in 25\% TAK patients $(95 \%$ CI 5-57\%, 12 patients, Fig. 2) using cyclosporine[64].

Tacrolimus One observational study reported at least partial clinical response in $20 \%$ TAK patients $(95 \%$ CI 3-56\%, 10 patients, Fig. 2) using tacrolimus[64]. 
a: Proportion of TAK with improvement on PET-CT

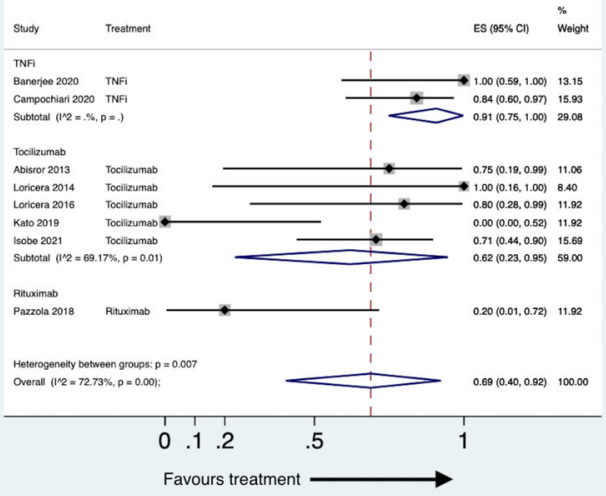

b: Proportion of TAK with normalization of ESR/ CRP

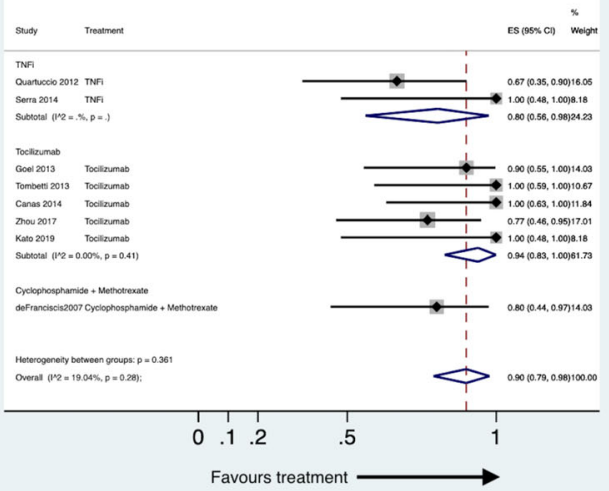

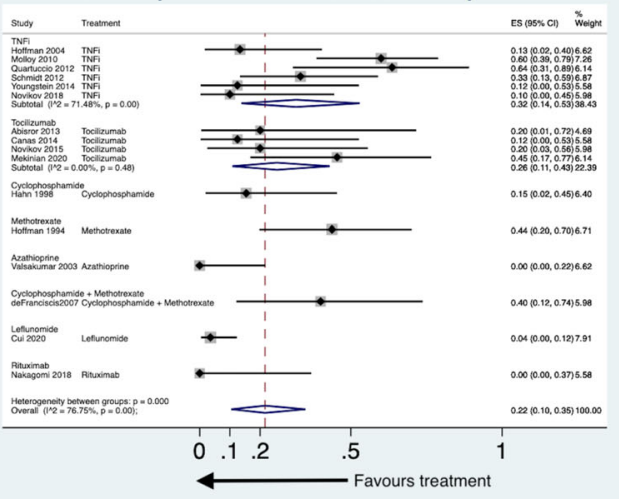

Fig. 4 Forest plot for proportions of patients with Takayasu arteritis (TAK) from observational studies with a improvement on PET-CT, b normalization of inflammatory markers and c relapses. 95\% CI 95\% confidence intervals, CRP C-reactive protein, ES effect size, ESR erythrocyte sedimentation rate, $\mathrm{PET}-\mathrm{CT}$ positron emission tomography computerized tomography, TNFi tumour necrosis factor alpha inhibitors
Cyclophosphamide and methotrexate A single observational study assessed responses in 10 TAK patients with a regimen of cyclophosphamide followed by methotrexate. At least a partial clinical response was observed in $80 \%$ (95\% CI 44 97\%, Fig. 2). Normalization of inflammatory markers was seen in $80 \%$ (95\% CI 44-97\%, Fig. 4b). Relapses were observed in $40 \%$ (95\% CI 12-74\%, Fig. 4c) [38].

\section{Biologic DMARDs}

Tocilizumab One RCT [72] with a longer-term open label follow-up [89] and 22 observational studies [46, 47, 49-51, $56,59,68-70,76-788084,85,87,90-92,95,98]$ evaluated tocilizumab in TAK. Eighteen patients each with relapsing TAK were randomized to receive tocilizumab $162 \mathrm{mg}$ subcutaneous weekly or matching placebo. In the primary ITT analysis, the hazard ratio (HR) for time to relapse with tocilizumab versus placebo was 0.41 (95\% CI 0.15 to 1.10$)$. Although the effect size was large in favour of tocilizumab, the results did not attain statistical significance at the $5 \%$ level of difference in this primary analysis. Using a per-protocol analysis, HR for time to relapse with tocilizumab versus placebo was 0.34
(95\% CI $0.11-1.00)$. At 24 weeks, relapse free rate $(95 \%$ CI) was 50.6 (25.4-75.8)\% with tocilizumab and 22.9 (0.4 45.4)\% with placebo. Tocilizumab was not associated with different risk of adverse events (risk ratio $1.27,95 \% \mathrm{CI}$ $0.82-1.98$ ) or serious adverse events (risk ratio $0.5,95 \% \mathrm{CI}$ 0.05-5.04) when compared with placebo [72]. A longer-term open-label extension of this trial was recently published, wherein patients in both arms were continued on tocilizumab until 96 weeks. There was significant lowering of daily prednisolone dose from study entry till 96 weeks (mean difference $-0.12,95 \%$ CI -0.154 to -0.087$) \mathrm{mg} / \mathrm{kg} /$ day. Nearly one-half of enrolled patients could reduce their dose of prednisolone below $0.1 \mathrm{mg} / \mathrm{kg} / \mathrm{day}$. Of the 28 patients for whom serial angiography could be assessed, only 4 showed progression of vascular involvement. Meaningful differences in quality of life parameters assessed by using the SF-36 were observed by 24 weeks and maintained till 96 weeks. The major adverse effect associated with tocilizumab was infections (218.8 per 100 person-years), serious adverse events occurred at 17.4 per 100 person-years; however, there were no deaths. Fourteen patients experienced relapses while being enrolled in the trial (relapse rate 29.4 per 100 person-years) [89]. Overall, the data 
from these two studies demonstrates promise for the use of tocilizumab in TAK in terms of reduction of relapses and glucocorticoid exposure, improvement in quality of life, as well as retardation of angiographic progression of disease in nearly $83 \%$ patients.

Pooling data available from observational studies, tocilizumab was effective in attaining at least a partial clinical response in $87 \%$ patients (95\% CI 77-94\%, 17 studies, 226 patients, $I^{2} 59.79 \%$, Fig. 2) although the results were heterogenous. Excluding Prieto-Pena 2020, $I^{2}$ reduced below 50\%. The pooled proportion of patients attaining angiographic stabilization with tocilizumab was $88 \%$ (95\% CI $74-98 \%, 12$ studies, 86 patients, $I^{2} 53.93 \%$, Fig. 3) with considerable heterogeneity. Excluding either of Tombetti 2013, Zhou 2017 or Mekinian 2018 decreased $I^{2}$ below 50\%. Improvement in PET-CT with tocilizumab was seen in $62 \%$ (95\% CI $23-$ $95 \%, 5$ studies, 33 patients, $I^{2} 69.17 \%$, Fig. 4 a) patients. The heterogeneity was entirely explainable due to Kato 2019. Normalization of inflammatory markers was seen in nearly all patients (94\%, 95\% CI 83-100\%, 5 studies, 43 patients, $I^{2} 0 \%$, Fig. 4b). Normalization of CRP with tocilizumab is due to a direct effect of the drug on CRP production from the liver and no more reliably reflects systemic inflammation in patients treated with tocilizumab [100]. Relapses were seen in $26 \%$ (95\% CI 11-43\%, 4 studies, 34 patients, $I^{2} 0 \%$, Fig. 4c) patients treated with tocilizumab over follow-up durations ranging from 6 to 18.5 months. Patients on tocilizumab could obtain a reduction in median prednisolone dose by $83 \%$ (95\% CI $71-92 \%, 5$ studies, $I^{2}$ 65.94\%, Supplementary Fig. 3a) or mean daily corticosteroid doses by $73 \%$ (95\% CI $62-82 \%, 8$ studies, $I^{2} 51.29 \%$, Supplementary Fig. 3b), although estimates were heterogenous. For reduction in mean prednisolone dose, excluding either of Canas 2014, Loricera 2014, Kato 2019 or Kilic 2020 reduced $I^{2}$ below 50\%. However, exclusion of individual studies could not ameliorate heterogeneity for pooled estimates of mean prednisolone dose. Separately, Gon et al. reported a reduction in mean prednisolone dose by $9.7 \mathrm{mg} 1$ year following tocilizumab therapy [84]. The pooled proportion of patients experiencing any adverse effect with tocilizumab was $23 \%$ (95\% CI 12-35\%, 13 studies, 162 patients, $I^{2} 53.84 \%$, Supplementary Fig. 2a) with considerable heterogeneity between estimates. $I^{2}$ dropped below $50 \%$ by excluding either of Mekinian 2018 or Mekinian 2020. The two studies comparing tocilizumab with TNF inhibitors [55, $80]$ or with other comparators $[69,78,90]$ shall be discussed subsequently.

TNF inhibitors The various tumour necrosis factor alpha (TNF) inhibitors (TNFi) used in TAK have been infliximab, etanercept, adalimumab, golimumab and certolizumab pegol. We have considered this evidence for TNFi as a whole rather than for individual TNFi. Nineteen observational studies evaluated TNFi in TAK $[36,37,40,43-45,48,52,54,55,61,62$,
73, 74, 79-81, 88, 98]. Pooling data across studies, TNFi were effective in attaining at least partial clinical response in $81 \%$ patients (95\%CI 72-89\%, 15 studies, 208 patients, $I^{2}$ 50\%, Fig. 2) with significant heterogeneity across studies. Excluding either of Kleinmann 2017, Novikov 2018, Banerjee 2020 or Mertz 2020 reduced $I^{2}$ below $50 \%$. The proportion of patients attaining angiographic stabilization of TAK was $86 \%$ (95\% CI 74-95\%, 10 studies, 148 patients, $I^{2}$ $61.52 \%$, Fig. 3 ) with considerable heterogeneity across studies. $I^{2}$ reduced below $50 \%$ by excluding either Schmidt 2012 or Tombetti 2013 from the pooled data. Improvement in PETCT was seen in 91\% (95\% CI 75-100\%, 2 studies, 26 patients, $I^{2}$ not assessable, Fig. 4a). Park et al. reported a decrease in median (interquartile range) of PET Vascular Activity Score from $12(11-15.5)$ to $11(8-12)$ with infliximab therapy over a follow-up period of 30 weeks[74]. Normalization of inflammatory markers was seen in $80 \%$ (95\% CI 56-98\%, 2 studies, 17 patients, $I^{2}$ not assessable, Fig. 4b). Relapses were seen in $32 \%$ (95\% CI 14-53\%, 6 studies, 87 patients, $I^{2} 71.48 \%$, Fig. 4c) with heterogenous estimates across studies of varying follow-up durations. The pooled percentage reduction before and after TNFi in median prednisolone dose was $81 \%$ (95\% CI $61-95 \%, 8$ studies, $I^{2} 79.85 \%$, Supplementary Fig. 3a), in mean prednisolone dose was $61 \%$ (95\%CI 49-73\%, 3 studies, $I^{2}$ not assessable, Supplementary Fig. 3b), with considerable heterogeneity across studies. The pooled proportion of patients with adverse events was 19\% (95\%CI 10-31\%, 12 studies 187 patients, $I^{2} 64.30 \%$, Supplementary Fig. 2a) with significant heterogeneity. However, excluding any individual study did not reduce the $I^{2}$ below $50 \%$ for outcomes of relapses, adverse events or median reduction of prednisolone dose. Quartuccio et al. assessed improvement in healthrelated quality of life measured using the 36-item short-form (SF-36) questionnaire in ten patients before and after infliximab in 10 patients with TAK. They observed significant improvement in bodily pain, general health and vitality components of the SF-36 [44].

The three studies comparing TNFi with other DMARDs $[55,61,80]$ shall be discussed subsequently.

Abatacept Abatacept blocks co-stimulatory signals to $\mathrm{T}$ lymphocytes, thereby exerting its anti-inflammatory activity. A single RCT has evaluated abatacept in TAK. Using a withdrawal design, patients were initially administered intravenous abatacept $(10 \mathrm{mg} / \mathrm{kg})$ at day 1, 15, 29 and thereafter at 8 weeks. After a period of 12 weeks, those who were in remission were randomized to receive abatacept $(n=11)$ or matching intravenous placebo $(n=$ 15 ) every 4 weeks. At 12 months, $22 \%$ on abatacept (and $40 \%$ on placebo) were in remission. Both arms had similar median duration of remission (5.5 months abatacept, 5.7 months placebo) and similar proportions of adverse events [63]. Overall, the data supporting the use of 
abatacept is not promising, as opposed to GCA where encouraging results have been found [101].

Rituximab Two observational studies assessed rituximab in TAK [71, 75]. The pooled proportion of patients with at least a partial clinical response was 68\% (95\% CI 41$91 \%, 15$ patients, Fig. 2). One study each assessed angiographic stabilization $(57 \%, 95 \%$ CI 18-90\%, 7 patients, Fig. 3) [75], reduction of disease activity assessed by PET-CT $(20 \%$, 95\% CI 1-72\%, 5 patients, Fig. 4a) [75] and relapses $(0 \%, 95 \%$ CI $0-37 \%, 8$ patients, Fig. 4c) [71]. Nakagomi et al. reported reduction in median prednisolone dose by $76 \%$ (95\% CI 57-89\%, Supplementary Fig. 3a)[71]. Pazzola et al. reported reduction in mean prednisolone dose by 65\% (95\% CI 45-80\%, Supplementary Fig. 3b) [75]. Adverse events were observed in $14 \%$ patients $(95 \%$ CI $0-39 \%, 2$ studies, 15 patients, Supplementary Fig. 2a). Heterogeneity could not be quantified for any of these pooled results due to paucity of studies.

\section{Small molecules and natural products}

Tofacitinib One observational study reported the use of tofacitinib in 5 patients with TAK. At least a partial clinical response was observed in $80 \%$ (95\% CI 28-99\%, Fig. 2), and angiographic stabilization seen in 60\% (95\% CI 15-95\%, Fig. 3 ). Reduction in mean prednisolone dose of $27 \%$ (95\% CI $12-$ $51 \%$, Supplementary Fig. 3b) following tofacitinib was observed. None of the patients had adverse events (95\% CI 0 52\%, Supplementary Fig. 2a)[86].

Resveratrol Resveratrol is a naturally occurring compound with demonstrable in vitro anti-TNF activity, evaluated in a RCT involving 220 patients with TAK (112 resveratrol, 108 placebo). At 12 weeks, the reduction in mean Birmingham Vasculitis Activity Score (BVAS) was greater in patients treated with resveratrol (29 to 4 ) when compared with placebo (28 to 24 ). The study had high risk of bias. The follow-up duration was too short to be meaningful, there was no assessment of angiographic progression and safety data was unavailable [66].

Curcumin Curcumin is another naturally occurring compound which has in vitro anti-TNF activity, evaluated in a RCT involving 246 patients with TAK (120 curcumin, 126 placebo). At 4 weeks, BVAS scores decreased significantly in the curcumin group, whereas they remained similar in the placebo group. The study had high risk of bias. Short follow-up duration, lack of assessment of angiography and lack of safety data were further limitations of the study [65].

\section{Studies comparing DMARDs}

Methotrexate with cyclophosphamide Two observational studies compared methotrexate with cyclophosphamide [60, 67]. There was no difference in the proportion of patients attaining at least partial clinical response at 6 months with methotrexate or cyclophosphamide (pooled risk ratio for methotrexate versus cyclophosphamide 1.01 , 95\% CI $0.7-$ $1.45,22$ patients on methotrexate and 51 on cyclophosphamide, $I^{2} 0 \%$, Supplementary Fig. 4a). One of the studies assessed angiographic stabilization; there were no differences between the two drugs (risk ratio for methotrexate versus cyclophosphamide 1.07 , 95\% CI 0.79-1.43, 12 patients on methotrexate and 46 on cyclophosphamide). Whereas wall enhancement on magnetic resonance angiography reduced in the patients treated with cyclophosphamide, there was no change observed in methotrexate-treated patients. However, stenosis or wall thickening did not differ in serial follow-up in either group. Greater reductions in mean ITAS2010 were seen with cyclophosphamide (4.7) than with methotrexate (2.2) in this study. Three patients treated with cyclophosphamide discontinued the same due to adverse events (none with methotrexate). There was one death in the cyclophosphamide arm (none with methotrexate) [67].

Cyclophosphamide with Leflunomide Two observational studies compared cyclophosphamide with leflunomide; they are described separately[83, 94]. Dai et al. compared 78 patients treated with cyclophosphamide with 53 treated with leflunomide (further evaluated in 54 patients on cyclophosphamide and 23 on leflunomide after propensity score matching). The risk ratio for attaining at least partial clinical remission with cyclophosphamide versus leflunomide at 9 months was 0.2 (95\% CI 0.1-0.6; after matching 0.8, 95\% CI $0.3-2.1)$ and for complete remission was $0.3(95 \% \mathrm{CI}$ $0.1-0.6$; after matching $0.1,95 \%$ CI $0.0-0.6$ ). The risk ratio for all adverse events for cyclophosphamide compared to leflunomide was 5.78 (95\% CI 2.18-15.32). There was one death in the patients treated with leflunomide (none in the cyclophosphamide treated patients) [83]. Ying et al. compared 45 patients treated with cyclophosphamide with 47 treated with leflunomide (further evaluated in 34 patients on cyclophosphamide and 41 on leflunomide after propensity score matching). At 6 months, risk ratio for at least a partial clinical response for cyclophosphamide versus leflunomide was 0.3 (95\% CI 0.1-0.95) before matching and 0.33 (95\% CI $0.1-$ 1.1) after matching. Risk ratio for complete response for cyclophosphamide versus leflunomide was 0.21 (95\% CI 0.08 0.52 ) before matching and 0.20 (95\% CI 0.07-0.54) after matching. At 12 months, risk ratio for at least a partial clinical response for cyclophosphamide versus leflunomide was 0.23 (95\% CI 0.05-1.21) before matching and 0.70 (95\% CI 0.14 3.41) after matching. Risk ratio for complete response for 
cyclophosphamide versus leflunomide was 0.22 (95\% CI 0.08-0.65) before matching and 0.33 (95\% CI $0.11-1.01$ ) after matching. Similar proportions of unmatched patients attained angiographic stabilization with cyclophosphamide or leflunomide (risk ratio for cyclophosphamide versus leflunomide at 6 months $0.88,95 \%$ CI $0.74-1.05$, and at 12 months $0.91,95 \%$ CI $0.77-1.07)$. A higher risk of adverse events with cyclophosphamide was observed in the unmatched cohort (risk ratio for cyclophosphamide versus leflunomide 2.09, 95\% CI 1.10-3.96)[94]. Although some of these confidence intervals for clinical response crossed 1 , the magnitude of effect sizes favoured leflunomide over cyclophosphamide. Overall, leflunomide appeared to have a favourable clinical response and safety profile when compared with cyclophosphamide for induction of remission in TAK.

Leflunomide with other DMARDs A longer-term follow up [57] (for $43 \pm 7.6$ months) of an uncontrolled observational study on leflunomide in TAK previously discussed [42] compared 5 patients from the original cohort who continued leflunomide with seven others who were changed to other DMARDs (infliximab, adalimumab or azathioprine) during this time period. Similar proportions of angiographic stabilization were observed (risk ratio for leflunomide versus other DMARDs $1.4,95 \%$ CI $0.88-2.24)$. The median time to prednisolone withdrawal was 20.8 months for leflunomide and 34.1 for other DMARDs. Mean cumulative prednisolone dose was higher in other DMARD-treated patients $(13.3 \mathrm{~g})$ compared to leflunomide $(6.3 \mathrm{~g})[57]$.

Leflunomide with methotrexate A single observational study compared leflunomide (40 patients) with methotrexate (28 patients) in TAK. Similar proportions of patients attained clinical responses at 6 months (risk ratio for leflunomide versus methotrexate for at least partial clinical response 1.13, 95\% $0.88-1.46$, and for complete response $1.35,95 \%$ CI $0.91-$ 2.01, 28 methotrexate, 40 leflunomide), 9 months (risk ratio for leflunomide versus methotrexate for at least partial clinical response $1.07,95 \% 0.91-1.25$, and for complete response $1.16,95 \%$ CI $0.83-1.62,26$ methotrexate, 37 leflunomide) and 12 months (risk ratio for leflunomide versus methotrexate for at least partial clinical response $1.04,95 \% 0.88-1.23$, and for complete response 1.13, 95\% CI 0.83-1.54, 26 methotrexate, 37 leflunomide). Angiographic stabilization was similar in both groups (risk ratio for leflunomide versus methotrexate at 6 months $1.02,95 \%$ CI $0.90-1.16,28$ methotrexate, 40 leflunomide, and at 12 months $1.01 .95 \%$ CI $0.84-1.21,26$ methotrexate, 37 leflunomide). Frequency of relapses was similar in both groups at 12 months (risk ratio for leflunomide versus methotrexate $0.47,95 \%$ CI $0.08-2.61,26$ methotrexate, 37 leflunomide) with no difference in proportions of patients developing adverse effects (risk ratio for leflunomide versus methotrexate $1.05,95 \%$ CI $0.42-2.62,26$ methotrexate, 37 leflunomide) [93].

Hydroxychloroquine with other DMARDs A single cohort study compared 21 TAK patients treated with hydroxychloroquine (along with other DMARDs) with 29 others not receiving hydroxychloroquine. At 6 months, 19\% patients on hydroxychloroquine had progression of TAK on serial angiographic assessment, as opposed to $51.7 \%$ patients not receiving hydroxychloroquine. Hydroxychloroquine use was associated with reduced rate of angiographic progression (HR 0.27, 95\% CI 0.08-0.94) even when adjusted for confounding factors of age and concomitant administration of tocilizumab[96].

TNFi with tocilizumab Two observational studies provided comparative results for TNFi versus tocilizumab in TAK $[55,80]$. Similar proportions of patients attained at least a partial clinical response with either treatment at 12 months (pooled risk ratio for TNFi versus tocilizumab $0.97,95 \% \mathrm{CI}$ 0.58-1.62, 92 TNFi and 24 tocilizumab treatment courses, Supplementary Fig. 4b) with considerable heterogeneity between studies $\left(I^{2} 80.1 \%\right)$. Campochiaro et al. further observed similar risk of continuation of drug at 24 months (suggesting effectiveness, risk ratio for TNFi versus tocilizumab 1.63, 95\% CI 0.90-2.96, 61 TNFi and 17 tocilizumab treatment courses)[80]. Mekinian et al. observed similar proportions of vascular complications (risk ratio for TNFi versus tocilizumab $1.75,95 \%$ CI $0.23-13.08$ ), vascular interventions (risk ratio for TNFi versus tocilizumab $1.5,95 \%$ CI $0.20-11.47$ ) and adverse events (risk ratio for TNFi versus tocilizumab 1.08 , 95\% CI 0.36-3.29) during 56 courses of TNFi and 14 courses of tocilizumab treatment. Relapse-free survival at 3 years was similar (91\% for TNFi, 85.7\% for tocilizumab)[55].

Biologic DMARDs with conventional DMARDs Five observational studies compared biologic with conventional DMARDs $[55,61,69,78,90]$. Pooled risk ratio of clinical response with biologic versus conventional DMARDs was 1.99 (95\% CI 0.99-4.01, 2 studies, 41 biologic, 55 conventional, $I^{2} 0 \%$, Supplementary Fig. 4c) and for angiographic stabilization was 1.32 (95\% CI 0.98-1.78, 41 biologic, 55 conventional, $I^{2} 46.5 \%$, Supplementary Fig. 4d)[61, 69]. Kong et al. reported similar risk of adverse events with tocilizumab or cyclophosphamide (risk ratio for tocilizumab versus cyclophosphamide $1.67,95 \%$ CI $0.12-23.49$ ). Mean reduction in ITAS2010 was 3 for tocilizumab and 1.8 for cyclophosphamide treated patients. Median reduction in prednisolone dose following DMARD was $20 \mathrm{mg}$ in both groups[69]. Wang et al. compared outcomes in 27 patients treated with tocilizumab with 22 patients treated with cyclophosphamide at 6 months. The reported median ITAS 2010 scores at 6 months in both groups were similar ( 0 versus 0 ), so also were the median number of active items on NIH disease activity 
measures ( 0 versus 0$)$. Proportions of adverse events were higher with cyclophosphamide (54.5\%) than with tocilizumab $(22.2 \%)$. The study reported greater lowering of prednisolone dose in the tocilizumab group when compared with cyclophosphamide, although exact corticosteroid doses before and after were unclear [78]. Pan et al. compared 11 patients with TAK with coronary ostial stenosis treated with tocilizumab with 11 others treated with conventional DMARDs. At 6 months, median reduction in ITAS2010 was 8 in tocilizumab group as opposed to 2 in patients treated with conventional DMARDs. Median prednisolone dose reduction following treatment in both groups was $66.7 \%$. Median cumulative corticosteroid dose was lesser in tocilizumab-treated patients $(1.65 \mathrm{~g})$ when compared with those on conventional DMARDs (4.34 g), although the tocilizumab-treated patients had a much lower prednisolone dose at treatment onset (7.5 mg daily) when compared to the conventional DMARD arm (30 mg daily). Risk of adverse events was similar (risk ratio for tocilizumab versus conventional DMARDs 0.75, 95\% CI 0.22-2.60) [90]. Mekinian et al. observed a greater risk of relapses with conventional DMARDs at 3 years compared with biological DMARDs (HR for relapse-free survival $0.26,95 \%$ CI $0.09-0.73$ for biologic versus conventional DMARDs). Patients on conventional DMARDs developed more vascular complications over 3 years $(16.6 \%)$ when compared with biological DMARDs $(5.1 \%)[55]$.

\section{Adverse event profile of DMARDs}

The proportions of adverse effects with individual drugs, where available, presented in Supplementary Fig. 2a have been discussed previously. A post hoc analysis looked at the frequency and profile of infectious adverse events. Proportions of patients developing infections with each drug in uncontrolled observational studies are presented in Supplementary Fig. $2 b$. The various infections encountered in different studies are summarized in Table 6. These were mainly respiratory, cutaneous and genitourinary infections, as well as reactivation of varicella zoster. The proportions of patients developing infectious adverse events with bDMARDs were numerically higher than those receiving cDMARDs.

\section{Certainty of outcomes}

Results are summarized in Table 7. The evidence for relapses, angiographic stabilization and reduction in prednisolone dose with tocilizumab, and for relapses and duration of remission for abatacept based on RCTs, were rated to be of moderate certainty due to some concerns about risk of bias for these studies (Table 3). For outcomes of reduction in Birmingham Vasculitis Activity Score with curcumin and resveratrol, as well as for all outcomes derived from controlled or uncontrolled observational studies, the certainty of evidence was either low or very low, due to nature of studies (observational), risk of bias, indirectness of evidence, imprecision of estimates and inconsistency across studies.

\section{DISCUSSION}

The present systematic review overviews the evidence base for the management of TAK with DMARDs. There is a paucity of high-quality studies to guide the medical management of TAK. Only four distinct RCTs were identified, of which two had considerable methodological flaws. The use of conventional DMARDs in TAK is based only on observational studies. The lack of a suitable comparator group for observational studies in TAK was an important consideration downgrading the quality of evidence base.

Uncontrolled observational studies reported at least partial clinical response and angiographic stabilization in nearly $80 \%$ patients. However, the sample size of individual studies was small. The possibility of selecting patients with favourable results for reporting in observational studies cannot be excluded. Therefore, the true proportion of patients demonstrating clinical or angiographic stabilization of active disease is likely smaller than that observed. Most studies assessed the effect on biologic drugs on a background of cDMARDs and prednisolone, whereas studies evaluating cDMARDs did so on a background of prednisolone therapy. Therefore, the estimates of improvement associated with each drug are likely to be overestimated. Hence, the findings of the meta-analyses need to be cautiously interpreted. The two RCTs of moderate quality failed to demonstrate statistically significant benefit with abatacept or tocilizumab in the primary analyses [63, 72]. However, the magnitude of the effect size and secondary per-protocol analyses favoured tocilizumab versus placebo. The longer-term open-label follow-up of the same RCT also demonstrated meaningful improvements in angiographic stabilization and better quality of life with tocilizumab [89].

There was considerable uncertainty over the effect sizes for clinical benefit and angiographic stabilization with DMARDs in TAK derived from uncontrolled studies. The 95\% CI in the pooled data were considerably wide for all DMARDS except for TNFi, tocilizumab and leflunomide. Nearly $20 \%$ patients relapsed in the pooled analyses for uncontrolled studies. In the RCT of abatacept in TAK where relapse was a primary outcome, there was no demonstrable benefit when compared with placebo. Therefore, the effectiveness of presently used DMARDs in reducing relapses is uncertain. Another limitation of the available literature on DMARDs in TAK was the use of background DMARDs in addition to the DMARD whose outcome was reported in the observational studies.

Most pooled estimates were heterogenous, possibly due to pooling of results across different studies comparing varying 
Table 6 Profile of infections with DMARDs in Takayasu arteritis

\begin{tabular}{|c|c|c|}
\hline Study* & Drug & Infections (number of episodes) \\
\hline \multicolumn{3}{|c|}{ Randomized controlled trials } \\
\hline Langford 2017 (63) & Abatacept & $\begin{array}{l}\text { URTI (2), sinusitis (2), otitis media (1), LRTI (2), cutaneous (1), } \\
\text { pyelonephritis (1), vaginal candidiasis (2), UTI (2) }\end{array}$ \\
\hline Nakaoka 2018 (72) & Tocilizumab & Infections (9) \\
\hline Nakaoka 2020 (89) & Tocilizumab & $\begin{array}{l}\text { Infections (32); serious infections (6): bacteremia (1), } \\
\text { gastroenteritis (2), LRTI (2), pyelonephritis (1) }\end{array}$ \\
\hline \multicolumn{3}{|c|}{ Controlled observational studies } \\
\hline \multirow[t]{2}{*}{ Sun 2017 (67) } & CYC & LRTI (3), UTI (1) \\
\hline & MTX & None \\
\hline \multirow[t]{2}{*}{ Dai 2020 (83) } & LEF & None \\
\hline & CYC & LRTI (3), fever (1) \\
\hline \multirow[t]{2}{*}{ Wu 2020 (93) } & LEF & LRTI (3), UTI (1) \\
\hline & MTX & LRTI (2), UTI (1) \\
\hline \multirow[t]{2}{*}{ Ying 2020 (94) } & LEF & LRTI (4), UTI (1) \\
\hline & $\mathrm{CYC}$ & LRTI (6), UTI (1), cutaneous (1) \\
\hline \multirow[t]{2}{*}{ Kong 2018 (69) } & Tocilizumab & None \\
\hline & $\mathrm{CYC}$ & None \\
\hline \multirow[t]{2}{*}{ Pan 2020 (90) } & Tocilizumab & None \\
\hline & cDMARDs & URTI (1) \\
\hline \multicolumn{3}{|c|}{ Uncontrolled observational studies } \\
\hline Shelhamer 1985 (32) & CYC & Cystitis (2), varicella zoster virus (1) \\
\hline Hoffman 1994 (33) & MTX & Pneumocystis jiroveci pneumonia \\
\hline Valsakumar 2003 (35) & AZA & None \\
\hline Shinjo 2007 (39) & MMF & None \\
\hline Goel 2010 (41) & MMF & Severe sepsis \\
\hline de Souza 2012 (42) & LEF & None \\
\hline Stern $2014(53)$ & CYC & $\begin{array}{l}\text { H1N1 influenza (1), cholecystitis (1), sinusitis (1), } \\
\text { gastroenteritis (1), E. coli sepsis (1) }\end{array}$ \\
\hline Li 2016 (58) & MMF & Hepatitis B virus reactivation (1) \\
\hline Cui $2020(82)$ & LEF & None \\
\hline Li 2020 (86) & Tofacitinib & None \\
\hline Nakagomi 2018 (71) & Rituximab & LRTI (1), invasive pulmonary aspergillosis (1) \\
\hline Pazzola 2018 (75) & Rituximab & None \\
\hline Hoffman 2004 (36) & TNFi & Histoplasmosis (1), varicella zoster virus (1) \\
\hline Baldissera 2007 (37) & TNFi & None \\
\hline Molloy 2008 (40) & TNFi & Viral infection (1), histoplasmosis (1) \\
\hline Mekinian 2012 (43) & TNFi & Cutaneous (1), Epstein Barr virus (1), pulmonary tuberculosis (1) \\
\hline Quartuccio 2012 (44) & TNFi & None \\
\hline Schmidt 2012 (45) & TNFi & LRTI (3), varicella zoster virus (1), pyelonephritis (1), postoperative infection (1) \\
\hline Tombetti 2013 (48) & TNFi & None \\
\hline Serra $2014(52)$ & TNFi & None \\
\hline Youngstein 2014 (54) & TNFi & None \\
\hline Kleinmann 2017 (62) & TNFi & None \\
\hline Novikov 2018 (73) & TNFi & Herpes labialis (2), LRTI (1), tonsillitis (1), UTI (1), postoperative abscess (1) \\
\hline Campochiaro 2020 (81) & TNFi & Varicella zoster virus (6), UTI (3), gastroenteritis (1) \\
\hline Mertz 2020 (88) & TNFi & Pyelonephritis (2), otitis media (1) \\
\hline Park 2018 (74) & TNFi & URTI (3), viral keratitis (1) \\
\hline Erbasan $2020(98)$ & TNFi, Tocilizumab & Serious infections (3), tubercular lymphadenitis (1) (in the entire cohort) \\
\hline Goel 2013 (47) & Tocilizumab & UTI (1), URTI (1) \\
\hline
\end{tabular}


Table 6 (continued)

\begin{tabular}{lll}
\hline Study* & Drug & Infections (number of episodes) \\
\hline Tombetti $2013(48)$ & Tocilizumab & Recurrent respiratory infections \\
Canas 2014 (50) & Tocilizumab & None \\
Loricera 2014 (51) & Tocilizumab & None \\
Novikov 2015 (56) & Tocilizumab & LRTI (3), varicella zoster virus (1) \\
Loricera 2016(59) & Tocilizumab & None \\
Zhou 2017 (68) & Tocilizumab & UTI (1) \\
Mekinian 2018 (70) & Tocilizumab & Dental abscess (1) \\
Shah 2019 (77) & Tocilizumab & Postoperative infection (1) \\
Gon 2020 (84) & Tocilizumab & None \\
Kilic 2020 (85) & Tocilizumab & None \\
Mekinian 2020 (87) & Tocilizumab & URTI (3), viral gastroenteritis (2), UTI (1), varicella zoster virus (1) \\
Prieto-Pena 2020 (91) & Tocilizumab & LRTI (2), varicella zoster virus (1), abdominal sepsis (1) \\
Wang 2020 (92) & Tocilizumab & None \\
Isobe 2021 (95) & Tocilizumab & LRTI (1) \\
\hline
\end{tabular}

*Studies which did not report infections are not mentioned here

AZA azathioprine, $C D M A R D s$ conventional disease-modifying antirheumatic drugs, $C Y C$ cyclophosphamide, $L E F$ leflunomide, $M T X$ methotrexate, $M M F$ mycophenolate mofetil, TNFi tumour necrosis factor alpha inhibitors, $L R T I$ lower respiratory tract infection, URTI upper respiratory tract infection, UTI urinary tract infection

interventions. The small sample size of most uncontrolled observational studies could also explain the observed heterogeneity [102]. Since there is a lack of consensus on the definition of active disease in TAK [2], studies used varying definitions of clinical remission. Outcomes were reported by studies at different time periods. These factors might have also contributed towards the observed heterogeneity in pooled estimates. Some heterogeneity could be reduced by excluding individual studies from the pooled estimates, as discussed in the results.

Only two studies assessed improvements in quality of life with DMARDs[44, 89]. The importance of patient-reported outcomes (PRO) in Rheumatology is being increasingly recognized[103]. The need to evaluate changes in PROs with pharmacotherapy in TAK is an avenue for further research.

Few studies compared DMARDs in TAK. Such comparisons were only available from observational studies. For the comparisons between conventional DMARDs, most were equivalent, except for potentially better benefits with leflunomide when compared with cyclophosphamide as observed in observational studies with matching between the two cohorts. Limited evidence suggested potential for better clinical and angiographic responses with biologic DMARDs when compared with conventional DMARDs, based on the observed effect size. However, statistical significance of this difference was not observed at the 5\% level of difference. Tocilizumab and TNFi appeared to be equivalent with respect to clinical benefits observed. Comparing pooled proportions of adverse events (including infections) in uncontrolled studies of DMARDs, these adverse events appeared more prevalent with bDMARDs than with cDMARDs. However, the $95 \%$ confidence intervals of these estimates considerably overlapped.

The paucity of high-quality evidence to guide the management of TAK requires to be kept in mind when developing guidelines for TAK management. As a consequence, guideline development in TAK might require greater reliance on consensus expert opinion rather than high-quality evidence.

Since TAK is a rare disease, high-quality RCTs of adequate statistical power will likely require multicentric, possibly multinational collaborative efforts to come into fruition. Future observational studies on TAK reporting treatment outcomes should attempt to include an appropriate control group, while controlling for the effect of important prognostic variables while assessing outcomes using statistical techniques. This shall improve the quality of evidence drawn from observational studies in TAK.

The use of a variety of outcome measures in studies of TAK is another limitation. The authors opine that there is a need to include at least clinical and angiographic measures of disease activity while reporting studies on management of TAK. Relapses on treatment and reduction of corticosteroid dose following therapy are also critical outcome measures, in our opinion.

Understanding the pathogenesis of TAK might enable the targeting of future therapies in TAK. A case in point is the prevalent literature on the use of TNFi and tocilizumab in TAK [104, 105]. Increasingly, T helper 17 cells and interleukin-17 are being recognized as potential drivers of inflammation in TAK [106-108]. Therapies targeting the T 


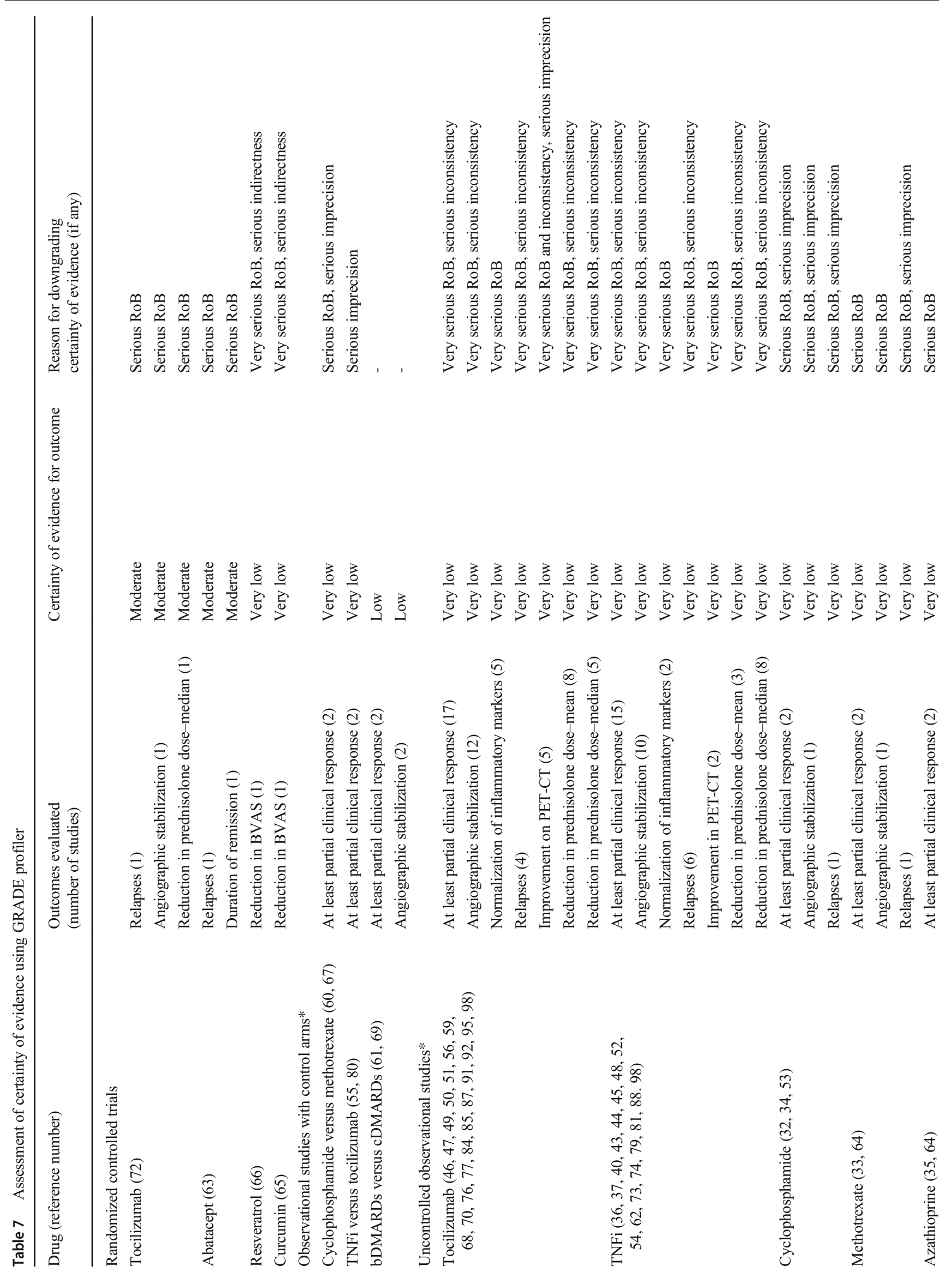


政
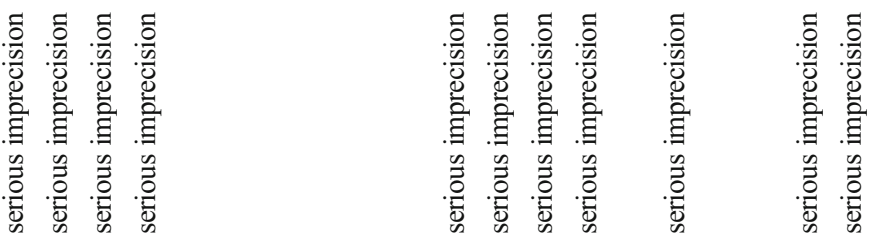

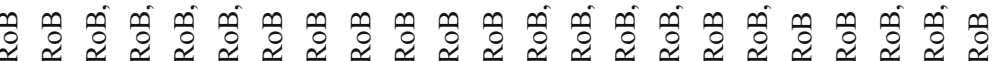
岂 施

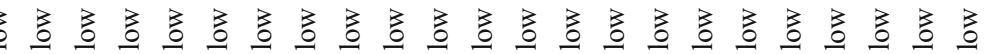

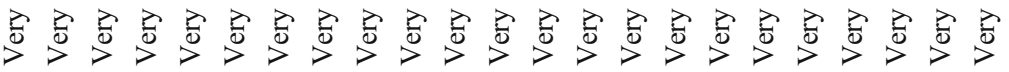

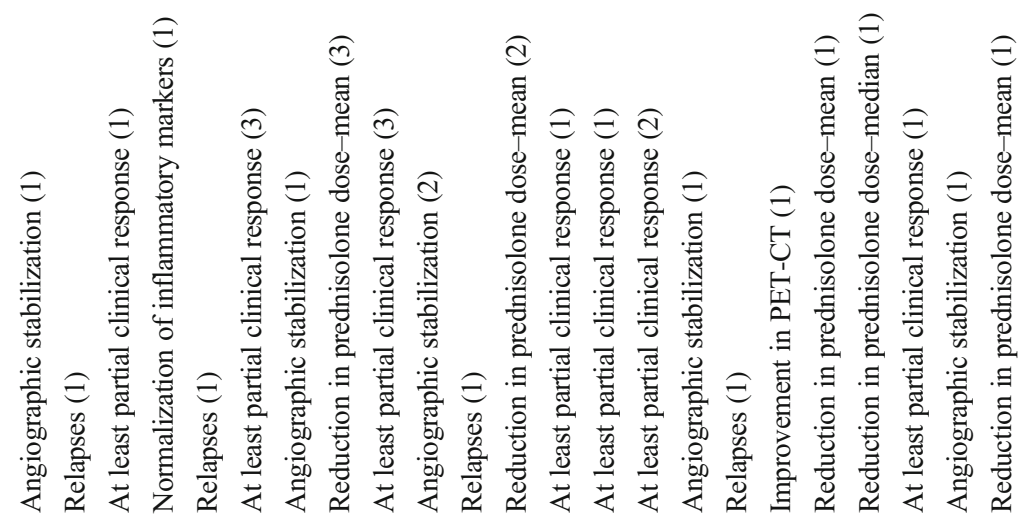

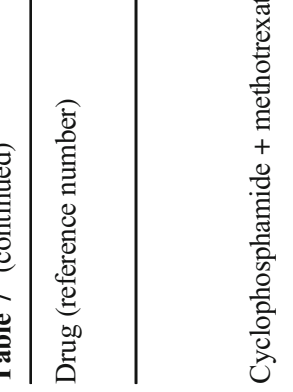

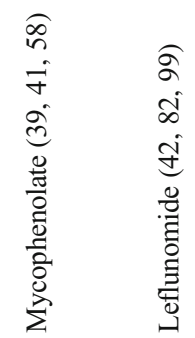

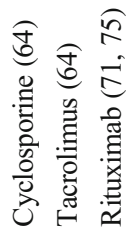

0
0
0
0
0
0

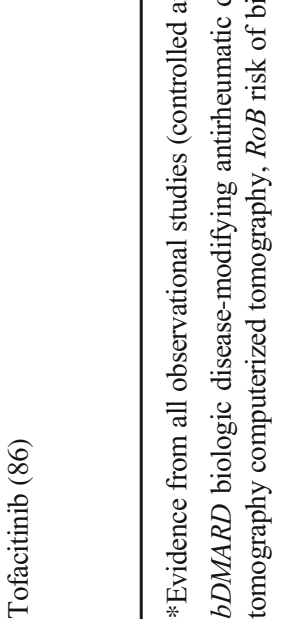


helper 17- interleukin-17 axis are already being used in other rheumatic diseases[109] and may further be explored in TAK. Janus kinase inhibitors target multiple downstream inflammatory pathways and are increasingly being used in rheumatic diseases[110]. Although evidence for their use in TAK is scant [86], it is reasonable to explore their role further based on understanding of biology and ease of administration when compared to biologic therapies.

There were limitations to our systematic review. The review protocol was not registered in PROSPERO, although it was pre-published [11]. The review protocol was modified post hoc to consider clinical and composite outcome measures together as well as to analyse reduction in prednisolone dose following DMARD therapy, proportions of patients with infections following DMARD therapy and outcomes based on DMARD subtype as secondary outcomes. However, protocol modifications were clearly identified. The choice of studies reporting outcomes on at least 5 patients was arbitrary. However, this limit was set keeping in view the rarity of TAK when compared with other rheumatic diseases. The meta-analysis technique using score test and Freeman-Tukey double arcsine transformation to pool proportions allowed us to pool proportions of either 0 or 1 . However, this limited the evaluation of study heterogeneity using $I^{2}$, which could be assessed if there were more than three studies. While some studies reported a reduction in inflammatory markers before and after therapy, they did not report proportions of patients with normalization of inflammatory markers, which was our outcome of interest. Similarly, some studies enumerated numbers of adverse events or infections but did not delineate recurrent events in the same individual. Hence, proportions of adverse events or infections from these studies could not be included in our systematic review. We considered the outcomes at the last available time point for our analyses, since studies reported outcomes at varying time periods. An individual patient data meta-analysis and assessment of the effectiveness of corticosteroid therapy or endovascular interventions alone were beyond the scope of our review.

\section{CONCLUSION}

The current evidence base to guide management of TAK with DMARDs is scarce. While tocilizumab, TNFi and leflunomide show promise, the quality of evidence to support their use is low. There is a need for high-quality observational studies with well-selected comparable control arms as well as multicentric RCTs of adequate power to guide the management of TAK with DMARDs.

Abbreviations $95 \%$ CI, 95\% confidence intervals; ACR, American College of Rheumatology; ADA, Adalimumab; APLAR, Asia-Pacific
League of

Associations for Rheumatology; AZA, Azathioprine; BVAS, Birmingham Vasculitis Activity Score; CENTRAL, Cochrane Controlled Register of Trials; CER, Certolizumab; CsA, Cyclosporine; CYC, Cyclophosphamide; DMARD, Disease-modifying anti-rheumatic drugs; bDMARD, Biologic DMARD; cDMARD, Conventional DMARD; ETAN, Etanercept; EULAR, European Alliance of Associations

for Rheumatology; GCA, Giant cell arteritis; GOL, Golimumab; GRADE, Grading of Recommendations, Assessment, Development and Evaluations; HCQ, Hydroxychloroquine; IFX, Infliximab; ITAS2010, Indian Takayasu Clinical Activity Score 2010; LEF, Leflunomide; MMF, Mycophenolate mofetil; MTX, Methotrexate; NIH, National Institutes of Health; NOS, Newcastle-Ottawa scale; PET-CT, Positron Emission

Tomography Computerized Tomography; PRISMA, Preferred Reporting Items for Systematic Reviews and Meta-analyses; PRISMA-S, PRISMA amendment to include multiple database searches; PRO, Patient-reported outcomes; PROSPERO, Prospective International

Register of Systematic Reviews; QOL, Quality of life; RoB, Risk of bias; RCT, Randomized controlled trial; TAC, Tacrolimus; TAK, Takayasu arteritis; TNFi, Tumour necrosis factor alpha inhibitors; WHO ICTRP, World Health Organization International Clinical Trials Registry Platform

Acknowledgements Durga Prasanna Misra would like to acknowledge the support of his late father Dr. Sasanka Sekhar Misra for his academic endeavours.

Author contribution Conception and design of the study, acquisition of data, analysis and interpretation of data-DPM, UR, PP, VA, AS; drafting the article - DPM, UR, PP; revising the article critically for important intellectual content-VA, AS; final approval of the version to be submitted - DPM, UR, PP, VA, AS; agreement to be accountable for all aspects of the work in ensuring that questions related to the accuracy or integrity of any part of the work are appropriately investigated and resolved-DPM, UR, PP, VA, AS.

Funding Durga Prasanna Misra acknowledges support from the Indian Council of Medical Research (Grant No 5/4/1-2/2019-NCD-II) for his research on Takayasu arteritis.

\section{Declarations}

Ethics approval This article does not contain any studies with human participants or animals performed by any of the authors.

Disclosures None.

\section{References}

1. Misra DP, Agarwal V (2020) The perennial search for alternatives to corticosteroids in rheumatology: is there light at the end of the tunnel? Clin Rheumatol 39:2845-2848. https://doi.org/10.1007/ s10067-020-05357-0

2. Misra DP, Wakhlu A, Agarwal V, Danda D (2019) Recent advances in the management of Takayasu arteritis. Int J Rheum Dis 22(Suppl 1):60-68. https://doi.org/10.1111/1756-185x.13285

3. Misra DP, Misra R (2015) Assessment of disease activity in Takayasu's arteritis. Indian J Rheumatol 10:S43-S47. https://doi. org/10.1016/j.injr.2015.08.006 
4. OCEBM Levels of Evidence Working Group*. "The Oxford 2011 Levels of Evidence". Oxford Centre for Evidence-Based Medicine. http://www.cebm.net/index.aspx?o=5653 [Accessed on 01 March 2021]

5. Kelley GA, Kelley KS (2019) Systematic reviews and metaanalysis in rheumatology: a gentle introduction for clinicians. Clin Rheumatol 38:2029-2038. https://doi.org/10.1007/s10067019-04590-6

6. Pacheco RL, Latorraca COC, de Souza AWS, Pachito DV, Riera $\mathrm{R}$ (2017) Clinical interventions for Takayasu arteritis: a systematic review. Int J Clin Pract 71. https://doi.org/10.1111/ijcp.12993

7. Barra L, Yang G, Pagnoux C (2018) Non-glucocorticoid drugs for the treatment of Takayasu's arteritis: a systematic review and meta-analysis. Autoimmun Rev 17:683-693. https://doi.org/10. 1016/j.autrev.2018.01.019

8. Misra DP, Sharma A, Kadhiravan T, Negi VS (2017) A scoping review of the use of non-biologic disease modifying antirheumatic drugs in the management of large vessel vasculitis. Autoimmun Rev 16:179-191. https://doi.org/10.1016/j.autrev. 2016.12.009

9. Ferfar Y, Mirault T, Desbois AC, Comarmond C, Messas E, Savey L, Domont F, Cacoub P, Saadoun D (2016) Biotherapies in large vessel vasculitis. Autoimmun Rev 15:544-551. https:// doi.org/10.1016/j.autrev.2016.02.012

10. Dua AB, Kalot MA, Husainat NM, Byram K, Springer JM, James KE, Chang Lin Y, Turgunbaev M, Villa-Forte A, Abril A, Langford C, Maz M, Chung SA, Mustafa RA (2021) Takayasu arteritis: a systematic review and meta-analysis of test accuracy and benefits and harms of common treatments. ACR Open Rheumatol 3:80-90. https://doi.org/10.1002/acr2.11186

11. Rathore U, Patro P, Agarwal V, Sharma A, Misra DP (2021) Disease modifying antirheumatic drugs for the management of Takayasu arteritis - protocol for a systematic review. Indian J Rheumatol 16:79-82

12. Higgins JPT, Thomas J, Chandler J, Cumpston M, Li T, Page MJ, Welch VA (2019) Cochrane Handbook for Systematic Reviews of Interventions. 2nd Edition. Chichester (UK): John Wiley \& Sons.

13. Moher D, Liberati A, Tetzlaff J, Altman DG, Group P (2009) Preferred reporting items for systematic reviews and meta-analyses: the PRISMA statement. PLoS Med 6:e1000097-e1000097. https://doi.org/10.1371/journal.pmed.1000097

14. Rethlefsen ML, Kirtley S, Waffenschmidt S et al (2021) PRISMA-S: an extension to the PRISMA Statement for Reporting Literature Searches in Systematic Reviews. Syst Rev 10:39. https://doi.org/10.1186/s13643-020-01542-z

15. Arend WP, Michel BA, Bloch DA, Hunder GG, Calabrese LH, Edworthy SM, Fauci AS, Leavitt RY, Lie JT, Lightfoot RW Jr, Masi AT, McShane DJ, Mills JA, Stevens MB, Wallace SL, Zvaifler NJ (1990) The American College of Rheumatology 1990 criteria for the classification of Takayasu arteritis. Arthritis Rheum 33:1129-1134. https://doi.org/10.1002/art.1780330811

16. Ishikawa K (1988) Diagnostic approach and proposed criteria for the clinical diagnosis of Takayasu's arteriopathy. J Am Coll Cardiol 12:964-972. https://doi.org/10.1016/0735-1097(88)90462-7

17. Sharma BK, Jain S, Suri S, Numano F (1996) Diagnostic criteria for Takayasu arteritis. Int J Cardiol 54(Suppl):S141-S147

18. Ozen S, Pistorio A, Iusan SM, Bakkaloglu A, Herlin T, Brik R, Buoncompagni A, Lazar C, Bilge I, Uziel Y, Rigante D, Cantarini L, Hilario MO, Silva CA, Alegria M, Norambuena X, Belot A, Berkun Y, Estrella AI, Olivieri AN, Alpigiani MG, Rumba I, Sztajnbok F, Tambic-Bukovac L, Breda L, al-Mayouf S, Mihaylova D, Chasnyk V, Sengler C, Klein-Gitelman M, Djeddi D, Nuno L, Pruunsild C, Brunner J, Kondi A, Pagava K, Pederzoli S, Martini A, Ruperto N, for the Paediatric Rheumatology International Trials Organisation (PRINTO) (2010) EULAR/ PRINTO/PRES criteria for Henoch-Schönlein purpura, childhood polyarteritis nodosa, childhood Wegener granulomatosis and childhood Takayasu arteritis: Ankara 2008. Part II: Final classification criteria. Ann Rheum Dis 69:798-806. https://doi.org/10. 1136/ard.2009.116657

19. Kerr GS, Hallahan CW, Giordano J, Leavitt RY, Fauci AS, Rottem M, Hoffman GS (1994) Takayasu arteritis. Ann Intern Med 120:919-929

20. Misra R, Danda D, Rajappa SM, Ghosh A, Gupta R, Mahendranath KM, Jeyaseelan L, Lawrence A, Bacon PA, Indian Rheumatology Vasculitis (IRAVAS) group (2013) Development and initial validation of the Indian Takayasu Clinical Activity Score (ITAS2010). Rheumatology (Oxford) 52:1795-1801. https://doi.org/10.1093/rheumatology/ket128

21. Sterne JAC, Savović J, Page MJ, Elbers RG, Blencowe NS, Boutron I, Cates CJ, Cheng HY, Corbett MS, Eldridge SM, Emberson JR, Hernán MA, Hopewell S, Hróbjartsson A, Junqueira DR, Jüni P, Kirkham JJ, Lasserson T, Li T, McAleenan A, Reeves BC, Shepperd S, Shrier I, Stewart LA, Tilling K, White IR, Whiting PF, Higgins JPT (2019) RoB 2: a revised tool for assessing risk of bias in randomised trials. BMJ 366:14898. https://doi.org/10.1136/bmj.14898

22. Newcastle-Ottawa scale. http://www.ohri.ca/programs/clinical epidemiology/oxford.asp [Accessed on 14 July 2020]

23. Li L, Liu C, Cheng L, Yan S, Chen H, Li Y (2021) Assessment of diagnostic utility, clinical phenotypic associations, and prognostic significance of anti-NXP2 autoantibody in patients with idiopathic inflammatory myopathies: a systematic review and meta-analysis. Clin Rheumatol 40:819-832. https://doi.org/10.1007/s10067020-05291-1

24. Misra DP, Agarwal V (2018) Systematic reviews: challenges for their justification, related comprehensive searches, and implications. J Korean Med Sci 33:9. https://doi.org/10.3346/jkms.2018. 33.e92

25. Lin L, Chu H (2018) Quantifying publication bias in meta-analysis. Biometrics 74:785-794. https://doi.org/10.1111/biom.12817

26. GRADEpro GDT: GRADEpro Guideline Development Tool [Software]. McMaster University, 2020 (developed by Evidence Prime, Inc.). Available from gradepro.org. [Accessed on 04 September 2020]

27. Online calculator for pooling variances. https://home.ubalt.edu/ ntsbarsh/business-stat/otherapplets/Pooled.htm [Accessed on 04 September 2020].

28. Nyaga VN, Arbyn M, Aerts M (2014) Metaprop: a Stata command to perform meta-analysis of binomial data. Arch Public Health 72:39. https://doi.org/10.1186/2049-3258-72-39

29. Practical Meta-analysis effect size calculator. Available at https:// campbellcollaboration.org/escalc/html/EffectSizeCalculatorSMD1.php [Accessed on 04 September 2020]

30. Morales E, Pineda C, Martínez-Lavín M (1991) Takayasu's arteritis in children. J Rheumatol 18:1081-1084

31. Misra DP, Aggarwal A, Lawrence A, Agarwal V, Misra R (2015) Pediatric-onset Takayasu's arteritis: clinical features and shortterm outcome. Rheumatol Int 35:1701-1706. https://doi.org/10. 1007/s00296-015-3272-7

32. Shelhamer JH, Volkman DJ, Parrillo JE, Lawley TJ, Johnston MR, Fauci AS (1985) Takayasu's arteritis and its therapy. Ann Intern Med 103:121-126. https://doi.org/10.7326/0003-4819103-1-121

33. Hoffman GS, Leavitt RY, Kerr GS, Rottem M, Sneller MC, Fauci AS (1994) Treatment of glucocorticoid-resistant or relapsing Takayasu arteritis with methotrexate. Arthritis Rheum 37:578582. https://doi.org/10.1002/art.1780370420

34. Hahn D, Thomson PD, Kala U, Beale PG, Levin SE (1998) A review of Takayasu's arteritis in children in Gauteng, South Africa. Pediatr Nephrol 12:668-675. https://doi.org/10.1007/ s004670050526 
35. Valsakumar AK, Valappil UC, Jorapur V, Garg N, Nityanand S, Sinha N (2003) Role of immunosuppressive therapy on clinical, immunological, and angiographic outcome in active Takayasu's arteritis. J Rheumatol 30:1793-1798

36. Hoffman GS, Merkel PA, Brasington RD, Lenschow DJ, Liang P (2004) Anti-tumor necrosis factor therapy in patients with difficult to treat Takayasu arteritis. Arthritis Rheum 50:2296-2304. https:// doi.org/10.1002/art.20300

37. Baldissera E, Dagna L, Tiraboschi M et al (2007) Anti-TNF alpha agents in Takayasu's arteritis: an Italian experience. Ann Rheum Dis 66:376-376

38. de Franciscis S, Serra R, Luongo A, Sabino G, Puzziello A (2007) The management of Takayasu's arteritis: personal experience. Ann Vasc Surg 21:754-760. https://doi.org/10.1016/j.avsg.2007.03. 021

39. Shinjo SK, Pereira RMR, Tizziani VAP, Radu AS, Levy-Neto M (2007) Mycophenolate mofetil reduces disease activity and steroid dosage in Takayasu arteritis. Clin Rheumatol 26:1871-1875. https://doi.org/10.1007/s10067-007-0596-z

40. Molloy ES, Langford CA, Clark TM, Gota CE, Hoffman GS (2008) Anti-tumour necrosis factor therapy in patients with refractory Takayasu arteritis: long-term follow-up. Ann Rheum Dis 67: 1567-1569. https://doi.org/10.1136/ard.2008.093260

41. Goel R, Danda D, Mathew J, Edwin N (2010) Mycophenolate mofetil in Takayasu's arteritis. Clin Rheumatol 29:329-332. https://doi.org/10.1007/s10067-009-1333-6

42. De Souza AWS, Da Silva MD, MacHado LSG, Oliveira ACD, Pinheiro FAG, Sato EI (2012) Short-term effect of leflunomide in patients with Takayasu arteritis: an observational study. Scand J Rheumatol 41:227-230. https://doi.org/10.3109/03009742.2011. 633553

43. Mekinian A, Néel A, Sibilia J et al (2012) Efficacy and tolerance of infliximab in refractory Takayasu arteritis: French multicentre study. Rheumatology (Oxford) 51:882-886. https://doi.org/10. 1093/rheumatology/ker380

44. Quartuccio L, Schiavon F, Zuliani F, Carraro V, Catarsi E, Tavoni AG, Bombardieri S, Punzi L, de Vita S (2012) Long-term efficacy and improvement of health-related quality of life in patients with Takayasu's arteritis treated with infliximab. Clin Exp Rheumatol 30:922-928

45. Schmidt J, Kermani TA, Bacani AK, Crowson CS, Matteson EL, Warrington KJ (2012) Tumor necrosis factor inhibitors in patients with Takayasu arteritis: Experience from a referral center with long-term followup. Arthritis Care Res 64:1079-1083. https:// doi.org/10.1002/acr.21636

46. Abisror N, Mekinian A, Lavigne C, Vandenhende MA, Soussan M, Fain O (2013) Tocilizumab in refractory Takayasu arteritis: a case series and updated literature review. Autoimmun Rev 12: 1143-1149. https://doi.org/10.1016/j.autrev.2013.06.019

47. Goel R, Danda D, Kumar S, Joseph G (2013) Rapid control of disease activity by tocilizumab in 10 'difficult-to-treat' cases of Takayasu arteritis. Int J Rheum Dis 16:754-761. https://doi.org/ 10.1111/1756-185x.12220

48. Tombetti E, Baldissera E, Franchini S, Motta F, Aiello P, Cavalli G, Sabbadini MG (2013) Efficacy of anti-TNF therapy in 15 patients with refractory Takayasu's arteritis: long term unicentric follow-up. Ann Rheum Dis 71:226. https://doi.org/10.1136/ annrheumdis-2012-eular.2174

49. Tombetti E, Franchini S, Papa M, Sabbadini MG, Baldissera E (2013) Treatment of refractory takayasu arteritis with tocilizumab: 7 Italian patients from a single referral center. J Rheumatol 40: 2047-2051. https://doi.org/10.3899/jrheum.130536

50. Canas CA, Canas F, Izquierdo JH et al (2014) Efficacy and safety of anti-interleukin 6 receptor monoclonal antibody (tocilizumab) in Colombian patients with Takayasu arteritis. J Clin Rheumatol 20:125-129. https://doi.org/10.1097/rhu.0000000000000098
51. Loricera J, Blanco R, Castaneda S et al (2014) Tocilizumab in refractory aortitis: a study on 16 patients and literature review. Clin Exp Rheumatol 32:S79-S89. https://doi.org/10.1136/ annrheumdis-2014-eular.2984

52. Serra R, Grande R, Buffone G, Scarcello E, Tripodi F, Rende P, Gallelli L, de Franciscis S (2014) Effects of glucocorticoids and tumor necrosis factor-alpha inhibitors on both clinical and molecular parameters in patients with Takayasu arteritis. J Pharmacol Pharmacother 5:193-196. https://doi.org/10.4103/0976-500X. 136101

53. Stern S, Clemente G, Reiff A, Ramos MPR, Marzan KA, Terreri MT (2014) Treatment of pediatric Takayasu arteritis with infliximab and cyclophosphamide: experience from an American-Brazilian cohort study. J Clin Rheumatol 20:183-188. https://doi.org/10.1097/RHU.0000000000000106

54. Youngstein T, Peters JE, Hamdulay SS, Mewar D, Price-Forbes A, Lloyd M, Jeffery R, Kinderlerer AR, Mason JC (2014) Serial analysis of clinical and imaging indices reveals prolonged efficacy of TNF-alpha and IL-6 receptor targeted therapies in refractory Takayasu arteritis. Clin Exp Rheumatol 32:S11-S18

55. Mekinian A, Comarmond C, Resche-Rigon M, Mirault T, Kahn JE, Lambert M, Sibilia J, Néel A, Cohen P, Hie M, Berthier S, Marie I, Lavigne C, Anne Vandenhende M, Muller G, Amoura Z, Devilliers H, Abad S, Hamidou M, Guillevin L, Dhote R, Godeau B, Messas E, Cacoub P, Fain O, Saadoun D, French Takayasu Network (2015) Efficacy of biological-targeted treatments in Takayasu arteritis multicenter, retrospective study of 49 patients. Circulation 132:1693-1700. https://doi.org/10.1161/ circulationaha.114.014321

56. Novikov P, Smitienko I, Elonakov A, Koilubaeva G, Moiseev S (2015) Safety and efficacy of short-term treatment with tocilizumab in patients with refractory Takayasu arteritis. Ann Rheum Dis 74:302. https://doi.org/10.1136/annrheumdis-2015eular.6048

57. de Souza AWS, Agustinelli RD, Almeida HD et al (2016) Leflunomide in Takayasu arteritis - a long term observational study. Rev Bras Reumatol Engl Ed 56:371-375. https://doi.org/ 10.1016/j.rbr.2015.09.007

58. Li J, Yang YJ, Zhao JL, Li MT, Tian XP, Zeng XF (2016) The efficacy of Mycophenolate mofetil for the treatment of Chinese Takayasu's arteritis. Sci Rep 6:7. https://doi.org/10.1038/ srep38687

59. Loricera J, Blanco R, Hernández JL, Castañeda S, Humbría A, Ortego N, Bravo B, Freire M, Melchor S, Mínguez M, Salvatierra J, González-Vela C, Calvo-Río V, Santos-Gómez M, Pina T, González-Gay MA (2016) Tocilizumab in patients with Takayasu arteritis: a retrospective study and literature review. Clin Exp Rheumatol 34:S44-S53

60. Aeschlimann FA, Eng SWM, Sheikh S, Laxer RM, Hebert D, Noone D, Twilt M, Pagnoux C, Benseler SM, Yeung RSM (2017) Childhood Takayasu arteritis: disease course and response to therapy. Arthritis Res Ther 19:10. https://doi.org/10.1186/ s13075-017-1452-4

61. Gudbrandsson B, Molberg Ø, Palm Ø (2017) TNF inhibitors appear to inhibit disease progression and improve outcome in Takayasu arteritis; an observational, population-based time trend study. Arthritis Res Ther 19:99-99. https://doi.org/10.1186/ s13075-017-1316-y

62. Kleinmann JF, Arnaud L, Sauleau E et al (2017) Efficacy and safety of infliximab originator in patients with Takayasu arteritis within the RTU (temporary recommendation of use) in France. Ann Rheum Dis 76:611-612. https://doi.org/10.1136/ annrheumdis-2017-eular.1793

63. Langford CA, Cuthbertson D, Ytterberg SR, Khalidi N, Monach PA, Carette S, Seo P, Moreland LW, Weisman M, Koening CL, Sreih AG, Spiera R, McAlear CA, Warrington KJ, Pagnoux C, 
McKinnon K, Forbess LJ, Hoffman GS, Borchin R, Krischer JP, Merkel PA, for the Vasculitis Clinical Research Consortium, HajjAli R, Tuthill K, Gartner K, Madden L, Rice B, Matteson EL, Kermani T, Jaquith J, Amudala N, Clark-Cotton M, Messier S, Farquharson J, Jagadeesh S, McBride D, Venuturupalli S, Wallace D, Phan R, Verde N, Salinas D, Godina J, Davids M, Udeh U, Sejismundo L, Harris J (2017) A randomized, double-blind trial of abatacept (CTLA-4Ig) for the treatment of Takayasu arteritis. Arthritis Rheum 69:846-853. https://doi.org/10.1002/art.40037

64. Ohigashi H, Tamura N, Ebana Y, Harigai M, Maejima Y, Ashikaga T, Isobe M (2017) Effects of immunosuppressive and biological agents on refractory Takayasu arteritis patients unresponsive to glucocorticoid treatment. J Cardiol 69:774-778. https://doi.org/10.1016/j.jjcc.2016.07.009

65. Shao N, Jia H, Li Y, Li J (2017) Curcumin improves treatment outcome of Takayasu arteritis patients by reducing TNF- $\alpha$ : a randomized placebo-controlled double-blind clinical trial. Immunol Res 65:969-974. https://doi.org/10.1007/s12026-017-8917-z

66. Shi GX, Hua MH, Xu QW, Ren TL (2017) Resveratrol improves treatment outcome and laboratory parameters in patients with Takayasu arteritis: a randomized double-blind and placebocontrolled trial. Immunobiology 222:164-168. https://doi.org/10. 1016/j.imbio.2016.10.008

67. Sun Y, Ma L, Ma L, Kong X, Chen H, Lv P, Lin J, Liu H, Yan Y, Ji Z, Yang C, Dai S, Wan W, Zou Y, Jin X, Jiang L (2017) Cyclophosphamide could be a better choice than methotrexate as induction treatment for patients with more severe Takayasu's arteritis. Rheumatol Int 37:2019-2026. https://doi.org/10.1007/ s00296-017-3847-6

68. Zhou J, Chen Z, Li J et al (2017) The efficacy of tocilizumab for the treatment of Chinese Takayasu's arteritis. Clin Exp Rheumatol 35:171-175

69. Kong XF, Zhang XJ, Lv P, Cui X, Ma L, Chen H, Liu H, Lin J, Jiang L (2018) Treatment of Takayasu arteritis with the IL-6R antibody tocilizumab vs. cyclophosphamide. Int J Cardiol 266: 222-228. https://doi.org/10.1016/j.ijcard.2017.12.066

70. Mekinian A, Resche-Rigon M, Comarmond C, Soriano A, Constans J, Alric L, Jego P, Busato F, Cabon M, Dhote R, Estibaliz L, Koné-Paut I, Landron C, Lavigne C, Lioger B, Michaud M, Ruivard M, Sacre K, Gottenberg JE, Gaches F, Goulenok T, Salvarani C, Cacoub P, Fain O, Saadoun D, French Takayasu network (2018) Efficacy of tocilizumab in Takayasu arteritis: multicenter retrospective study of 46 patients. J Autoimmun 91:55-60. https://doi.org/10.1016/j.jaut.2018.04.002

71. Nakagomi D, Kronbichler A, Witte T, Mohammad AJ, Jayne DRW (2018) Comment on: Rituximab therapy for Takayasu arteritis: a seven patients experience and a review of the literature. Rheumatology (Oxford) 57:1309-1310. https://doi.org/10.1093/ rheumatology/kex493

72. Nakaoka $\mathrm{Y}$, Isobe $\mathrm{M}$, Takei S, Tanaka $\mathrm{Y}$, Ishii T, Yokota S, Nomura A, Yoshida S, Nishimoto N (2018) Efficacy and safety of tocilizumab in patients with refractory Takayasu arteritis: results from a randomised, double-blind, placebo-controlled, phase 3 trial in Japan (the TAKT study). Ann Rheum Dis 77:348-354. https://doi.org/10.1136/annrheumdis-2017-211878

73. Novikov PI, Smitienko IO, Sokolova MV, Alibaz-Oner F, Kaymaz-Tahra S, Direskeneli H, Moiseev SV (2018) Certolizumab pegol in the treatment of Takayasu arteritis. Rheumatology (Oxford) 57:2101-2105. https://doi.org/10.1093/ rheumatology/key197

74. Park EH, Lee EY, Lee YJ, Ha YJ, Yoo WH, Choi BY, Paeng JC, Suh HY, Song YW (2018) Infliximab biosimilar CT-P13 therapy in patients with Takayasu arteritis with low dose of glucocorticoids: a prospective single-arm study. Rheumatol Int 38:22332242. https://doi.org/10.1007/s00296-018-4159-1
75. Pazzola G, Muratore F, Pipitone N, Crescentini F, Cacoub P, Boiardi L, Spaggiari L, Comarmond C, Croci S, Saadoun D, Salvarani C (2018) Rituximab therapy for Takayasu arteritis: a seven patients experience and a review of the literature. Rheumatology (Oxford) 57:1151-1155. https://doi.org/10.1093/ rheumatology/kex249

76. Kato M, Okuda H, Kameda $\mathrm{T}$ et al (2019) The usefulness of $18 \mathrm{~F}$ fluorodeoxyglucose positron emission tomography CT (18F-FDG $\mathrm{PET} / \mathrm{CT}$ ) as an imaging biomarker in Takayasu arteritis treated with tocilizumab. Ann Rheum Dis 78:1758-1759. https://doi. org/10.1136/annrheumdis-2019-eular.4429

77. Shah K, Mason JC (2019) Real life experience of tocilizumab for Takayasu arteritis. Rheumatology (Oxford) 58:158-158

78. Wang T, Liao H (2019) Comparison of efficacy and safety between tocilizumab and cyclophosphamide in treating patients with Takayasu's arteritis. Rheumatology (Oxford) 58:1

79. Banerjee S, Quinn KA, Gribbons KB, Rosenblum JS, Civelek AC, Novakovich E, Merkel PA, Ahlman MA, Grayson PC (2020) Effect of treatment on imaging, clinical, and serologic assessments of disease activity in large-vessel vasculitis. J Rheumatol 47:99-107. https://doi.org/10.3899/jrheum.181222

80. Campochiaro C, Tomelleri A, Sartorelli S, Cavalli G, de Luca G, Baldissera E, Dagna L (2020) Drug retention and discontinuation reasons between seven biologics in patients with Takayasu arteritis. Semin Arthritis Rheum 50:509-514. https://doi.org/10.1016/j. semarthrit.2020.01.005

81. Campochiaro C, Tomelleri A, Sartorelli S, de Luca G, Sembenini C, Cavalli G, Mapelli P, Picchio M, Papa M, Baldissera E, Dagna L (2020) Efficacy and safety of infliximab-biosimilar in Takayasu arteritis (TAKASIM): a monocentric, observational, prospective, open-label study. Ann Rheum Dis 79:1527. https://doi.org/10. 1136/annrheumdis-2020-eular.3250

82. Cui X, Dai X, Ma L, Yang C, Tan W, Zhang L, Zhang Z, Feng X, Wu R, Zou Y, Zhou Z, Lu Y, Wang Y, Wu M, Li S, Wang L, Lin H, Dong Z, Fu W, Sun X, Wang C, Ding J, Lv P, Lin J, Jiang L, East China Takayasu Arteritis (ECTA) Collaboration Group (2020) Efficacy and safety of leflunomide treatment in Takayasu arteritis: case series from the East China cohort. Semin Arthritis Rheum 50: 59-65. https://doi.org/10.1016/j.semarthrit.2019.06.009

83. Dai X, Cui X, Sun Y, Ma L, Jiang L (2020) Effectiveness and safety of leflunomide compared with cyclophosphamide as induction therapy in Takayasu's arteritis: an observational study. Ther Adv Chronic Dis 11:11. https://doi.org/10.1177/ 2040622320922019

84. Gon Y, Yoshifuji H, Nakajima T, Murakami K, Nakashima R, Ohmura K, Mimori T, Terao C (2020) Long-term outcomes of refractory Takayasu arteritis patients treated with biologics including ustekinumab. Mod Rheumatol 31:678-683. https://doi.org/10. 1080/14397595.2020.1800560

85. Kiliç L, Karadağ Ö, Erden A et al (2020) Anti-interleukin-6 (Tocilizumab) therapy in takayasu's arteritis: a real life experience. Turk J Med Sci 50:31-36. https://doi.org/10.3906/sag-1906-39

86. Li J, Li M, Tian X, Zeng X (2020) Tofacitinib in patients with refractory Takayasu's arteritis. Rheumatology (Oxford) 59:e95e98. https://doi.org/10.1093/rheumatology/keaa281

87. Mekinian A, Saadoun D, Vicaut E et al (2020) Tocilizumab in treatment-naive patients with Takayasu arteritis: TOCITAKA French prospective multicenter open-labeled trial. Arthritis Res Ther 22:7. https://doi.org/10.1186/s13075-020-02311-y

88. Mertz P, Kleinmann JF, Lambert M, Puéchal X, Bonnin A, Boulon C, Diot E, Hachulla E, Harid N, Harle JR, Helder G, Kahn JE, Kone-Paut I, Lavigne C, Magy-Bertrand N, Maillard H, Martin T, Maurier F, Poindron V, Schleinitz N, Sibilia J, Arnaud L (2020) Infliximab is an effective glucocorticoidsparing treatment for Takayasu arteritis: results of a multicenter 
open-label prospective study. Autoimmun Rev 19:4. https://doi. org/10.1016/j.autrev.2020.102634

89. Nakaoka Y, Isobe M, Tanaka Y, Ishii T, Ooka S, Niiro H, Tamura N, Banno S, Yoshifuji H, Sakata Y, Kawakami A, Atsumi T, Furuta S, Kohsaka H, Suzuki K, Hara R, Maejima Y, Tsukamoto H, Takasaki Y, Yamashita K, Okada N, Yamakido S, Takei S, Yokota S, Nishimoto N (2020) Long-term efficacy and safety of tocilizumab in refractory Takayasu arteritis: final results of the randomized controlled phase 3 TAKT study. Rheumatology (Oxford) 59:2427-2434. https://doi.org/10.1093/ rheumatology/kez630

90. Pan L, Du J, Liu J et al (2020) Tocilizumab treatment effectively improves coronary artery involvement in patients with Takayasu arteritis. Clin Rheumatol 39:2369-2378. https://doi.org/10.1007/ s10067-020-05005-7

91. Prieto-Pena D, Calderon-Goercke M, Bernabeu P et al (2020) Tocilizumab in refractory Takayasu arteritis. open-label national multicenter study of 53 patients of clinical practice. Ann Rheum Dis 79: 1074-1075. https://doi.org/10.1136/annrheumdis-2020-eular.2445

92. Wang C, Song H, Yu Z, Quan M (2020) AB1009 The efficacy of tocilizumab on the treatment of Takayasu arteritis in Chinese children. Ann Rheum Dis 79:1798-171798. https://doi.org/10.1136/ annrheumdis-2020-eular.5778

93. Wu C, Sun Y, Cui X, Wu S, Ma L, Chen H, Yan Y, Ji Z, Liu Y, Lin J, Lv P, Chen R, Yang P, Jiang L (2020) Effectiveness and safety of methotrexate versus leflunomide in 12-month treatment for Takayasu arteritis. Ther Adv Chronic Dis 11: 204062232097523. https://doi.org/10.1177/2040622320975233

94. Ying S, Cui XM, Dai XM et al (2020) Efficacy and safety of leflunomide versus cyclophosphamide for initial-onset Takayasu arteritis: a prospective cohort study. Ther Adv Musculoskeletal Dis 12:11. https://doi.org/10.1177/1759720x20930114

95. Isobe M, Maejima Y, Saji M, Tateishi U (2021) Evaluation of tocilizumab for intractable Takayasu arteritis and $18 \mathrm{~F}$ fluorodeoxyglucose-positron emission tomography for detecting inflammation under tocilizumab treatment. J Cardiol 77:539-544. https://doi.org/10.1016/j.jjcc.2020.12.011

96. Rongyi C, Zongfei J, Jiang L, Sifan W, Lingying M, Ying S, Wenshu Y, Xiaomeng C, Xiufang K, Xiaomin D, Lili M, Yanshan L, Lindi J (2021) Effect of hydroxychloroquine on angiographic progression in routine treatment of Takayasu arteritis. Mod Rheumatol:1-17. https://doi.org/10.1080/14397595.2021.1879347

97. Wei Y, Zhao C, Liang J, et al. (2021) Factors associated with event-free survival in Chinese patients with Takayasu's arteritis. Clin Rheumatol. doi:https://doi.org/10.1007/s10067-020-05481-x

98. Erbasan F, Uçar İ, Aslan B, Yazisiz V, Terzioğlu ME (2021) The effects of biological agents on vascular structural lesions in Takayasu's arteritis. Clin Exp Rheumatol

99. Mustapha N, Barra L, Carette S, et al. (2020) Efficacy of leflunomide in the treatment of vasculitis. Clin Exp Rheumatol

100. Hirao M, Hashimoto J, Tsuboi H, Nampei A, Nakahara H, Yoshio N, Mima T, Yoshikawa H, Nishimoto N (2009) Laboratory and febrile features after joint surgery in patients with rheumatoid arthritis treated with tocilizumab. Ann Rheum Dis 68:654-657. https://doi.org/10.1136/ard.2008.090068

101. Langford CA, Cuthbertson D, Ytterberg SR, Khalidi N, Monach PA, Carette S, Seo P, Moreland LW, Weisman M, Koening CL, Sreih AG, Spiera R, McAlear CA, Warrington KJ, Pagnoux C, McKinnon K, Forbess LJ, Hoffman GS, Borchin R, Krischer JP, Merkel PA, for the Vasculitis Clinical Research Consortium, HajjAli R, Tuthill K, Gartner K, Madden L, Matteson EL, Kermani T, Jaquith J, Amudala N, Clark-Cotton M, Messier S, Farquharson J, Jagadeesh S, McBride D, Venuturupalli S, Wallace D, Phan R, Verde N, Salinas D, Godina J, Davids M, Udeh U, Sejismundo L, Harris J (2017) A randomized, double-blind trial of abatacept (CTLA-4Ig) for the treatment of giant cell arteritis. Arthritis Rheum 69:837-845. https://doi.org/10.1002/art.40044

102. IntHout J, Ioannidis JPA, Borm GF, Goeman JJ (2015) Small studies are more heterogeneous than large ones: a meta-meta-analysis. J Clin Epidemiol 68:860-869. https://doi.org/10.1016/j. jclinepi.2015.03.017

103. van Tuyl LHD, Boers M (2015) Patient-reported outcomes in core domain sets for rheumatic diseases. Nat Rev Rheumatol 11:705712. https://doi.org/10.1038/nrrheum.2015.116

104. Arnaud L, Haroche J, Mathian A, Gorochov G, Amoura Z (2011) Pathogenesis of Takayasu's arteritis: a 2011 update. Autoimmun Rev 11:61-67. https://doi.org/10.1016/j.autrev.2011.08.001

105. Castillo-Martínez D, Amezcua-Castillo LM, Granados J, Pineda C, Amezcua-Guerra LM (2020) Is Takayasu arteritis the result of a Mycobacterium tuberculosis infection? The use of TNF inhibitors may be the proof-of-concept to demonstrate that this association is epiphenomenal. Clin Rheumatol 39:2003-2009. https://doi.org/ 10.1007/s10067-020-05045-Z

106. Saadoun D, Garrido M, Comarmond C, Desbois AC, Domont F, Savey L, Terrier B, Geri G, Rosenzwajg M, Klatzmann D, Fourret P, Cluzel P, Chiche L, Gaudric J, Koskas F, Cacoub P (2015) Th1 and Th17 cytokines drive inflammation in takayasu arteritis. Arthritis Rheum 67:1353-1360. https://doi.org/10.1002/art.39037

107. Misra DP, Chaurasia S, Misra R (2016) Increased circulating Th17 cells, serum IL-17A, and IL-23 in Takayasu arteritis. Autoimmun Dis 8. https://doi.org/10.1155/2016/7841718

108. Misra DP, Negi VS (2016) Takayasu's arteritis. Indian J Rheumatol 11:73-77. https://doi.org/10.1016/j.injr.2016.04.001

109. Gracey E, Vereecke L, McGovern D, Fröhling M, Schett G, Danese S, de Vos M, van den Bosch F, Elewaut D (2020) Revisiting the gut-joint axis: links between gut inflammation and spondyloarthritis. Nat Rev Rheumatol 16:415-433. https:// doi.org/10.1038/s41584-020-0454-9

110. Choy EH (2019) Clinical significance of Janus Kinase inhibitor selectivity. Rheumatology (Oxford) 58:953-962. https://doi.org/ 10.1093/rheumatology/key339

Publisher's note Springer Nature remains neutral with regard to jurisdictional claims in published maps and institutional affiliations. 